\title{
Shape optimisation of manufacturable and usable cold-formed steel singly-symmetric and open columns
}

\author{
Bin Wang ${ }^{(1)^{\star}}$, Benoit P. Gilbert ${ }^{(1)}$, Hong Guan ${ }^{(1)}$ and Lip H. Teh ${ }^{(2)}$ \\ (1) Griffith School of Engineering, Gold Coast Campus, Griffith University, QLD 4222, Australia \\ (2) School of Civil, Mining and Environmental Engineering, University of Wollongong, NSW 2522, Australia \\ ${ }^{*}$ Corresponding author, Email: b.wang@griffith.edu.au
}

\section{ABSTRACT}

This paper aims at incorporating manufacturing and assembly features into a shape optimisation algorithm for cold-formed steel (CFS) profiles. Genetic algorithm (GA) is used as the search algorithm and is combined with the augmented Lagrangian constraint-handling method to avoid illconditioning. Manufacturable cross-sections are arbitrarily drawn in the initial generation and subsequently treated as an integral part of the GA. The assembly features considered in the study reflect the ones commonly encountered in the construction industry. They include fastening elements (horizontal flange and vertical web) and allowances for utilities, and are treated as constraints. The algorithm is applied to simply-supported singly-symmetric, free-to-warp open section columns with various numbers of manufacturing bends. Three assembly cases for half sections are investigated: (a) a horizontal flange, (b) a horizontal flange and a vertical web, and (c) a horizontal flange and a vertical web with a utility clearance. A two-step optimisation process is used to optimise the columns: (i) the optimum positions of the fastening elements (horizontal flange and vertical web) are determined first and (ii) the cross-sectional shapes are then optimised. The optimised columns are discussed and compared to the unconstrained optimised columns and the conventional lipped Cee-sections. The results demonstrate the robustness and efficiency of the algorithm. 


\section{KEYWORDS}

Shape optimisation; Cold-formed steel structures; Manufacturable cross-sections; Assembly constraints; Genetic Algorithm. 


\section{INTRODUCTION}

Cold-formed steel (CFS) members, having a high strength-to-weight ratio [1], have been widely used in engineered structures such as low-to-medium rise buildings and storage racks where hotrolled steel profiles have been proven uneconomic. CFS members are manufactured by bending thin-walled steel coils at room temperature to the desired cross-sectional shapes. These light-gauge structural components provide flexible member profiles for architects and engineers, and facilitate onsite manufacturing and/or installation.

Finding new and optimised cross-sections can significantly enhance the member capacity and reduce costs compared to the commonly used "Cee", "Zed" and "Sigma" shapes. However, previous research efforts on shape optimisation of CFS members usually focused on unconstrained solutions [2-8], leading to cross-sections that cannot be manufactured by the current cold-forming processes and/or be used in construction.

Recently, manufacturing constraints have been introduced into shape optimisation algorithms for CFS members in [9-12]. This inclusion resulted in cross-sections with a marginal reduction in the member capacity relative to their unconstrained counter-parts. Franco et al. [12] developed a grammar-based model to shape optimise CFS open profiles in which the manufacturing features, with given stiffener sizes, were intrinsically considered in the algorithm. Leng et al. [9] and Wang et al. [10] incorporated manufacturing constraints into CFS shape optimisation algorithms by allowing limited numbers of roll-forming bends per cross-section. Handling constraints, however, may add complexity to the algorithm and cause convergence issues. For this reason, Wang et al. [11] have improved their own algorithm and proposed a method of incorporating the manufacturing features as an integral part of the algorithm, addressing the challenges of dealing with manufacturing constraints. 
For assembly purposes, Leng et al. $[13,14]$ introduced end-use constraints into a stochastic shape optimisation algorithm, namely simulated annealing (SA). The constraints include singly-symmetry or point-symmetry, number of rollers (bends), vertical webs located at the mid-point (mid-height) of the cross-section, parallel flanges, rear lips and utility pass-through allowance. Both short (610 $\mathrm{mm})$ to long $(4,880 \mathrm{~mm})$ columns were investigated. The SA converged to singly-symmetric crosssections for short and intermediate columns and to point-symmetric cross-sections with large number of rollers for long columns.

The present study focuses on incorporating manufacturing and assembly features into the published GA-based "self-shape" optimisation algorithm for CFS columns [4,5]. The algorithm is applied to simply-supported singly-symmetric, free-to-warp open section columns. Manufacturing features, defined in [10], are incorporated into the algorithm as an intrinsic part of the cross-sections. Assembly features, defined in this paper, are introduced as constraints into the fitness function. Two main types of assembly features, aimed at creating cross-sections that can be practically used on site, are taken into account by having (i) fastening elements (horizontal flange and/or vertical web elements) to connect the profile to adjacent structures/elements and (ii) a clearance distance in the open part of the cross-section to allow utilities passage. The optimised cross-sections are discussed and compared to their unconstrained counter-parts and the conventional lipped Cee-sections.

\section{SHAPE-OPTIMISATION ALGORITHM}

\subsection{Overview}

This paper employs the previously developed GA-based shape optimisation algorithm $[4,5]$, referred to as the "self-shape optimisation algorithm". The algorithm uses the coordinates $(x, y)$ of the floating points constituting the cross-sections to define the individuals in a given design space. The stochastic search algorithm yields superior off-springs that bear similarities to their parents in succeeding generations. An augmented Lagrangian constraint-handling method [15] is used to 
automatically control the penalty function coefficients to remain finite in order to avoid ill-conditioned solutions. Cross-over and mutation operators are performed on the floating points constituting a cross-section (see [4,5], Sections 2.4 and 2.5 for more details). As the problem is singly-symmetric, only half of the cross-section is considered by the GA operators. Nevertheless, the entire crosssection is used to calculate the member capacity presented in Section 3.1.

\subsection{Constraints}

\subsubsection{Manufacturing constraints}

The same manufacturing rules published in [10], emerged from the limitations of rolled-forming machines, are applied to the algorithm in this paper. The rules are:

(1) The minimum length $L_{\min }$ of a single straight cross-sectional element (i.e. between roll-forming bends) is equal to $10 \mathrm{~mm}$;

(2) The maximum number of straight cross-sectional elements is limited to 20 (i.e. a maximum number of 19 roll-forming bends per cross-section).

Sharp roll-forming bending corners are conservatively considered herein and actual internal bending radii can be determined prior to manufacture.

The new proposed method of allowing optimised cross-sections to be manufactured and initially published in Wang et. al [11] is used herein. Manufacturing rules are now introduced as an intrinsic part of the cross-sectional shapes. Specifically, instead of drawing the cross-sections in the first generation with short elements ( $2 \mathrm{~mm}$ long) and aligning them using the Hough transform to ultimately create manufacturable cross-sections as in [10], the cross-sections are initially drawn herein with a fixed number of longer elements of random sizes, directly resulting in manufacturable cross-sections. The cross-over and mutation operators keep the cross-sections manufacturable. More details on this intrinsic feature of the algorithm are given Sections 2.3 to 2.5. The number of 
elements are set by the manufacturer, and is less than or equal to the maximum possible number of elements defined in the Rule (2). The self-avoiding random walks method defined by Gilbert et al. [4] is used to generate the initial cross-sections (see Section 2.3). The cross-over and mutation operators are detailed in Sections 2.4 and 2.5, respectively.

\subsubsection{Assembly constraints}

Adjacent members are connected to columns at the horizontal flange, the vertical web or both. Additionally, columns are often designed with an "utility clearance", as per [16], allowing bridging system and/or conduits to pass through the web. While specific applications of CFS columns are not considered in this paper, three combinations of the assembly features introduced above are considered herein for undertaking a case study:

- Case I: One horizontal flange per half cross-section, with the flange at least $L_{\text {min,fas }}=25 \mathrm{~mm}$ long to connect a M12 bolt, as per [16];

- Case II: Case I with a vertical web per half cross-section, with the overall web at least $L_{\text {min,fas }}=$ $25 \mathrm{~mm}$ long also to connect a M12 bolt;

- Case III: Case II with utility allowance of a minimum overall clearance of $2 \times D_{\min }=30 \mathrm{~mm}$.

These cases have similar end-use purposes to those described in [14].

Fig. 1 illustrates the assembly constraints per half cross-section for Case III, with the $x$-axis being the axis of symmetry. The fastening elements are formed in the initial population (see Section 2.3 for more details). To satisfy the utility allowance constraint, the $y$-coordinate of the last crosssectional point $P_{4}$ on the horizontal flange and all the succeeding points shall be greater than the minimum utility distance $D_{\min }$ (also see Section 3.1) per half cross-section. The cross-over and mutation operators allow the fastening elements to remain horizontal and/or vertical, as explained in Sections 2.4 and 2.5 , respectively. 


\subsection{Initial population}

Manufacturable half cross-sections are arbitrarily drawn in the first generation within the design space of $x_{\max }=100 \mathrm{~mm} \times y_{\max }=100 \mathrm{~mm}$. The steps to create the manufacturable half crosssections in the initial population are revised from [4,5], and are given below when fastening elements are not considered:

- Step 1: Create the first element, as shown in Fig. 2 (a):

1.1 Set the starting point $P_{0}$ of the element on the symmetric $x$-axis of the design space at the coordinate $\left(x_{\max } / 4,0\right)$, i.e. at $(25 \mathrm{~mm}, 0 \mathrm{~mm})$ herein.

1.2 Randomly select the length $L_{e l e}$ of the element in the interval $\left[L_{\min }, L_{\max }\right.$, where $L_{\min }$ is set in Rule (1) in Section 2.2.1 and $L_{\max }$ is an arbitrary maximum length of the element, selected by a trial and error method to achieve an uniform distribution of the initial population (see Section 3.1 and [17] for more details).

1.3 Randomly select the orientation angle $\theta_{\text {ele }}$ of the element in the interval $\left[-45^{\circ}, 45^{\circ}\right]$ relative to the vertical direction.

1.4 Create the element.

- Step 2: Create a new element relative to the last built element, of the length randomly selected in the interval $\left[L_{\min }, L_{\max }\right]$ and of the direction randomly chosen in the interval $\left[-45^{\circ}\right.$, $45^{\circ}$, as illustrated in Fig. 2 (b).

- Step 3: Perform the following checks:

3.1 If the last built element intersects the cross-section or the boundary of the design space ( $x$ $=0, x=x_{\max }=100 \mathrm{~mm}, y=0$ or $y=y_{\max }=100 \mathrm{~mm}$ ), delete this element and go to Step 2. If this step is repeated more than 10 times per element, then the cross-section is considered to be self-trapped (see [1] for more details) and is subsequently removed.

3.2 Else, keep the element. 
3.2.1 If the number of elements is less than the pre-defined number per half cross-section $N_{\text {ele }}$ determined by the manufacturer, go to Step 2,

3.2.2 Else, a new cross-section is generated. Go to Step 4.

- Step 4: Check the number of individuals in the population.

4.1 If the number of individuals equals the target number of individuals per generation, then the initial population is created.

4.2 Else, go to Step 1.

When fastening elements are taken into account in the algorithm and an element is selected to be a flange or a web, the above steps are modified as follows:

- $L_{\min }$ in Step 2 is replaced by $L_{\text {min, fas }}$ that is set in Cases I and II of Section 2.2.2.

- The orientation of the element is set to be horizontal (flange) or vertical (web).

The elements are labelled sequentially, as shown in Fig. 1, from the first element (' 1 ') (with its first node on the symmetry axis) to the final element (' $N$ ele'). Similarly, the floating points representing the elements are sequentially ordered from point $P_{0}$ on the axis of symmetry to the last point $P_{\text {Nele }}$. In the algorithm, the horizontal flange is allowed to be located at any element except for the first element $(' 1$ '), and the vertical web to be at any element from the first element to the element before the horizontal flange.

\subsection{Cross-over operator}

The one-point cross-over operator used in this study is revised from Gilbert et al. [5] to keep the sections manufacturable and the fastening elements horizontal and vertical. Two parents, having the same number of elements and the same location of fastening elements, are selected for crossover. This guarantees that the two offsprings have the same number of elements and the same 
location of fastening elements as their parents, therefore keeping the set number of elements and location of the fastening elements by the manufacturer. The concept is illustrated in Fig. 3.

A cross-over point, having the same sequential point number on each of the two cross-sections, is randomly selected between the second and the second last points constituting the cross-sections. These two cross-over points are referred to as $P_{c 01}$ and $P_{c 02}$ for Parent 1 and Parent 2, respectively, and are shown in Fig. 3 (a). Two points $P_{t 1}$ and $P_{t 2}$ are then defined using a linear interpolation between $P_{c 01}$ and $P_{c 02}$ as [15],

$$
\begin{aligned}
& P_{t 1}=\delta P_{c 01}+(1-\delta) P_{c 02} \\
& P_{t 2}=\delta P_{c 02}+(1-\delta) P_{c 01}
\end{aligned}
$$

where $\delta$ is a random number in the interval $[0,1]$.

Two offsprings are created by stretching portions of the parents to the new points $P_{t 1}$ or $P_{t 2}$ as illustrated in Fig. 3 (b, c) and detailed in the steps below. The first offspring is formed using the lefthand part of Parent 1 (from its first point to $P_{c 01}$ ) and the right-hand part of Parent 2 (from $P_{c 02}$ to its last point), and the second offspring using the right hand part of Parent 1 (from $P_{\text {cor }}$ to its last point) and the left hand part of Parent 2 (from its first point to $P_{c o 2}$ ). The procedure of creating the first offspring is detailed below; a similar procedure applies to the second offspring:

- Step 1: The left-hand part of Parent 1 is linearly stretched vertically and horizontally, using its starting point $P_{0}$ as the fixed (reference) point, so its cross-over point $P_{c 01}$ matches point $P_{t 1}$ in Eq. (1) (see Fig. 3 (b)).

- Step 2: The right-hand part of Parent 2 is linearly stretched vertically and horizontally, using its end point $P_{\text {Nele }}$ as the fixed (reference) point, so its cross-over point $P_{c 02}$ matches point $P_{t 1}$ in Eq. (1) (see Fig. 3 (b)). 
- Step 3: The two parts created in Steps 1 and 2 are joined together and form the first offspring, as illustrated in Fig. 3 (b).

- Step 4: If the offspring intersects itself or the boundary of the design space, the offspring is deleted.

The above cross-over operator allows the length of all elements, including the fastening ones, to vary and therefore their length to be optimised. The starting point of the cross-section $P_{0}$ is a reference point common to all cross-sections and avoids having duplicate cross-sections with the exact same cross-sectional shape but different node coordinates. The end point of the crosssections $P_{\text {Nele }}$ is fixed during the cross-over operation but can mutate in Section 2.5, allowing new cross-sectional shape to be created.

Offsprings are created until the overall population is replaced. As the cross-over points $P_{c 01}$ and $P_{c o 2}$ have the same sequential point number for the two parents, the offsprings thus have the same number of elements as their parents. Stretching the cross-sections vertically and horizontally, and not rotating and scaling them as in [5], allows the fastening element to remain horizontal or vertical in the offsprings. Similar to [5], a cross-over probability of 0.8 is used in this study.

\subsection{Mutation operator}

The mutation operator allows a new cross-sectional shape to be created by changing the coordinates of one or more cross-sectional points. All points can mutate except for the starting point $P_{0}$. Similar to [5], each point has a probability of mutation of 0.01 . If a point mutates, the following steps, illustrated in Fig. 4, apply:

- Step 1: The point is randomly moved within a $20 \mathrm{~mm}$ radius circle from its original position. The radius is chosen as twice the minimum length of the manufacturable elements (see Section 2.2.1) and was found to adequately create new cross-sectional shapes for the overall 
dimensions of cross-sections optimised in this study. The new coordinates $\left(x_{0}, y_{0}\right)$ of the mutated point is calculated as a function of the coordinates $(x, y)$ of the original point as,

$$
\begin{aligned}
& x_{0}=r \times \cos \theta+x \\
& y_{0}=r \times \sin \theta+y
\end{aligned}
$$

where $r$ is the mutation radius randomly chosen in the interval $[0 \mathrm{~mm}, 20 \mathrm{~mm}]$ and $\theta$ is the mutation angle randomly chosen in the interval $\left[0^{\circ}, 360^{\circ}\right.$.

- Step 2: Perform the following checks.

2.1 If the cross-section intersects itself or the boundary of the design space, then move the point back to its original position $(x, y)$ and go to Step 1. If Step 2.1 is repeated more than 10 times, the point is not mutated.

2.2 If one of the two points of a fastening element is mutated, the second point of the element is also mutated and moved by the same vector of the mutated point so as to keep the fastening element horizontal or vertical.

\section{OPTIMISATION PROBLEM}

\subsection{General}

The algorithm is used to minimise the cross-sectional area $A_{s}$ of simply-supported singly-symmetric, free-to-warp open CFS columns subject to an axial compressive load $N^{\star}$ of $75 \mathrm{kN}$. The column length is set to $2 \mathrm{~m}$ and the wall-thickness to $1.2 \mathrm{~mm}$.

Numbers of cross-sectional elements per half-section $N_{\text {ele }}=4,6$ and 8 are investigated for each of the three assembly cases (see Section 2.2.2). A uniformly distributed initial population in terms of cross-sectional areas (see [17] for more details) is created. If the maximum element length $L_{\max }$ is 
too large relative to $N_{\text {ele }}$, the algorithm tends to generate large cross-sections that do not fit in the design space and therefore have difficulties creating the initial population. To address this issue, the maximum element length $L_{\max }$ was adjusted using a trial-and-error method based on the value of $N_{\text {ele. }}$. The different values of $L_{\max }$ chosen are reported in Table 1.

Ten runs are performed for each scenario being investigated to verify the robustness of the algorithm. The number of generations and individuals per generation is reported in Section 3.2. The yield stress $f_{y}$ is $450 \mathrm{MPa}$, the Young's modulus $E$ is $200 \mathrm{GPa}$ and the shear modulus $\mathrm{G}$ is $80 \mathrm{GPa}$.

The general fitness functions, suitable for GA, are expressed for the three assembly cases as,

For Cases I and II:

$$
f=\frac{A_{s}}{A_{\text {squash }}}+\alpha_{N} \max \left(0, \frac{N^{*}}{N_{c}}-1\right)+\sum_{i=1}^{N_{e l e}} \alpha_{L, i} \max \left(0, \frac{L_{m, i}}{L_{e, i}}-1\right)
$$

For Case III:

$$
f=\frac{A_{s}}{A_{\text {squash }}}+\alpha_{N} \max \left(0, \frac{N^{*}}{N_{c}}-1\right)+\sum_{i=1}^{N_{\text {ele }}} \alpha_{L, i} \max \left(0, \frac{L_{m, i}}{L_{e, i}}-1\right)+\sum_{j=P_{D}}^{P_{N} \text { ele }} \alpha_{D, j} \max \left(0, \frac{D_{\min }}{y_{j}}-1\right)(6)
$$

where $A_{\text {squash }}$ is the squash area, defined as the lower bound cross-sectional area of the profile,

$$
A_{\text {squash }}=\frac{N^{*}}{f_{y}}
$$

$\alpha_{N}, \alpha_{L, i}$ and $\alpha_{D, j}$ are the penalty factors associated with the capacity, the length of element $i$ and the utility clearance violations of point $j$, respectively. $L_{e, i}$ is the actual length of element $i$ and $L_{m, i}$ is the minimum allowable length of element $i$, either equals $L_{\text {min, fas }}$ for the fastening elements (see Cases I and II in Section 2.2.2) or $L_{\min }$ for the other elements (see the manufacturing Rule (1) in Section 
2.2.1). If a vertical web is located at the first element of the half cross-section, $L_{\text {min,fas }}$ is then divided by two making the total length of the web as $L_{\text {min,fas }}$.

In Eq. (6), $P_{D}$ is the last point number of the horizontal flange, $P_{\text {Nele }}$ is the total number of crosssectional points, and $y_{j}$ is the $y$-coordinate of point number $j . N_{c}$ is the nominal member capacity in compression evaluated by the Direct Strength Method (DSM) [18], as specified in Clause 7.2.1 of AS/NZS 4600 [19]. Therefore, the cross-sections are optimised for global, local and distortional buckling. The rules to automatically calculate $N_{c}$ for shape optimisation purpose as fully detailed in [5] are applied in the study. The open source software CUFSM [20] is used to perform elastic buckling analysis on the full cross-sections. To achieve required accuracy of analysis in CUFSM, the cross-sectional elements are subdivided into two or three segments of equal length, as defined in [10].

To avoid ill-conditioning, the fitness functions in Eqs. (5) and (6) are re-arranged in Eqs. (8) and (9), respectively, to be used in the algorithm with the augmented Lagrangian method [21], as,

For Cases I and II:

$$
f=\frac{A_{s}}{A_{\text {squash }}}+\frac{1}{2}\left\{\gamma N\left[\max \left(0, \frac{N^{*}}{N_{c}}-1+\mu N\right)\right]^{2}+\sum_{i=1}^{N_{e l e}} \gamma L, i\left[\max \left(0, \frac{L_{m, i}}{L_{e}, i}-1+\mu L, i\right)\right]^{2}\right\}
$$

For Case III:

$$
\begin{aligned}
& f=\frac{A_{s}}{A_{\text {squash }}}+\frac{1}{2}\left\{V N\left[\max \left(0, \frac{N^{*}}{N_{c}}-1+\mu N\right)\right]^{2}+\sum_{i=1}^{N_{e l e}} \gamma L, i \max \left(0, \frac{L_{m, i}}{L_{e}, i}-1+\mu L, i\right)\right]^{2} \\
& \left.+\sum_{j=P_{D}}^{P_{\text {Nele }}} Y_{D, j}\left[\max \left(0, \frac{D_{\min }}{y_{j}}-1+\mu_{D, j}\right)\right]^{2}\right\}
\end{aligned}
$$

where $\gamma_{N}, \gamma_{L, i}$ and $\gamma_{D, j}$ are the penalty function coefficients associated with the real parameters $\mu_{N}, \mu_{L, i}$ and $\mu_{D, j}$ for the capacity, the length of element $i$ and the utility distance of point $j$, respectively. Adeli 
and Cheng [21] recommended real parameters to be zero. Gilbert et al. [4] investigated the initial penalty function coefficients from 0.35 to 5 and eventually recommended the coefficient of 2 . The initial values of $\gamma_{N}=\gamma_{L, i}=\gamma_{D, j}=2$ and $\mu_{N}=\mu_{L, i}=\mu_{D, j}=0$ are therefore used in this paper. The penalty increasing constant is taken as $\beta=1.05$ and the convergence rate as $\rho=1.5$ [4].

\subsection{Two-step optimisation process}

The fastening elements, i.e. horizontal flange and vertical web, can be at various locations within a cross-section, and all possible locations need to be investigated to fully optimise the cross-section. Therefore, a two-step optimisation process is employed as below:

- Step 1: The location optimisation, solely aimed at finding the optimum locations of the fastening elements using a large population on a small number of iterations (generations), is performed first. All possible locations of the fastening elements are equally represented in the initial generation and compete to dominate the overall population. The optimum location of the fastening elements is found when all the individuals in the population have the fastening elements at the same location. This step is further articulated as follows:

1.1 Identify all possible locations of the fastening elements (vertical web and/or horizontal flange), as tabulated in Table 2, for all numbers of cross-sectional elements $\left(N_{\text {ele }}\right)$. Then perform the GA analysis in the following manner.

1.2 Create an initial population (Section 2.3) composed of an equal number of individuals from each identified fastening element locations in Step 1.1. The number of individuals per fastening element location is given in Table 3, aiming to keep the overall population to a reasonable size, but with no less than 200 individuals for diversity per fastening element location.

1.3 Rank all individuals based on the AL fitness function in Eq. (5) (Cases I and II) or (8) (Case III).

1.4 Select the two parents for the cross-over operator amongst all individuals using the roulette wheel. 
1.5 Reproduce the offsprings by performing the cross-over operator (outlined in Section 2.4) and the mutation operator (outlined in Section 2.5), and go to Step 1.4 until the entire new population is created.

1.6 Update the AL coefficients and go to Step 1.3 until the number of generations analysed, as given in Table 3 , is met.

- Step 2: The shape optimisation aiming to find the optimum cross-section using a small population and a large number of iterations is then performed. This step is articulated as follows:

2.1 Create the initial population (Section 2.3) with 500 individuals, all having the fastening elements located at the optimum location found in Step 1.

2.2 Perform the GA analysis detailed in $[4,5]$ using the cross-over and mutation operators described in Sections 2.4 and 2.5 over 80 generations.

2.3 Repeat Steps 2.1 and 2.2 over 10 runs.

\section{$4 \quad$ RESULTS AND DISCUSSIONS}

\subsection{Optimum location of fastening elements (Step 1)}

Figs. 5 and 6 plot the evolution of the average number of individuals per fastening element position over 10 runs for $N_{\text {ele }}=4$ for Cases I and II, respectively. Other configurations investigated show a similar trend to Figs. 5 and 6 , with the individuals of one fastening element position dominating the entire population in a relatively small number of generations. In Figs. 5 and 6, typically, two or three fastening element positions compete in the first 10 generations and one position starts dominating afterwards.

The optimum locations of the fastening elements for all configurations investigated are given in Table 3. For Case I, all 10 runs converge to the same location of the fastening elements. For Cases 
II and III, at least 8 out of 10 runs converge to the same location. These results demonstrate the consistency of the algorithm in finding the optimum position of the fastening elements. The optimum position of the horizontal flange is usually found at element 2,3 or 4 , while the optimum location of the vertical web is usually observed at element 1 or 2 .

\subsection{Convergence (Step 2)}

Fig. 7 illustrates the average fitness function $f$ in Eq. (5) for Case I (Fig. 7 (a)) and Case II (Fig. 7 (b)), and $f$ in Eq. (6) for Case III (Fig. 7 (c)), with $\alpha_{N}, \alpha_{L, i}$ and $\alpha_{D, j}=10$, over 10 runs. The average fitness $f$ in Fig. 7 is multiplied by $A_{\text {squash }}$ for the equations to converge to the optimum cross-sectional area. For comparison purposes, the constrained $\left(N_{e l e}=4,6\right.$ and 8 in this paper) and unconstrained (no assembly and manufacturing constraints published in [5]) cases are plotted. The comparison shows that the algorithm always converges to an optimised solution. The unconstrained case converges slightly faster than the constrained ones. The convergence rate of all constrained cases is similar to each other, in about 50 to 60 generations.

Based on the runs performed on a cluster consisting of a mixture of SGI Altix XE and SG ${ }^{\circledR}$ Rackable $^{\mathrm{TM}}$ C2114-4TY14 servers, with the set no more than eight computer cores used per run, the average computation time of the constrained cases is 30 minutes per generation. This compares with an average computational time of 45 minutes per generation when the Hough transform was used to formulate manufacturable cross-sections in the authors' previous work [10]. In Fig. 7, to obtain convergence, 30,000 solutions (up to 60 generations) were investigated, compared to 70,000 solutions (up to 140 generations) in [10].

\subsection{Average results}

Table 4 to Table 6 summarise the average results of the optimised solutions over 10 runs for all the cases investigated. The algorithm reasonably satisfies all the constraints, with the average violation 
on the element length and utility clearance constraints in Eqs. $(5,6)$ being close or equal to zero. The maximum constraint violation is found for Case III and $N_{e l e}=8$ (Table 6 ) on the utility clearance in Eq. (6), and is equal to $2.7 \times 10^{-3}$. The algorithm always converges to a consistent optimised solution, with a maximum CoV of $0.49 \%$ on the cross-sectional area for Case I and $N_{e l e}=8$ (Table 4). This outcome demonstrates the robustness of the algorithm. The most optimised unconstrained cross-section $\left(N_{e l e}=\infty\right.$ in Table 4 to Table 6$)$ has a higher average ultimate compressive stress, defined as the ratio between the capacity $N_{c}$ and the cross-section area $A_{s}$, than all assembly cases by up to $7 \%$. For each assembly case, the more the cross-sectional elements, the greater (more efficient) the average ultimate compressive stress is. As the assembly cases become more complex, i.e. from Case I to Case III, the average ultimate compressive stress of the optimised solutions usually decreases to satisfy the constraints, as illustrated in Fig. 8. Case I and Case II yield similar (within $0.3 \%$ ) average ultimate compressive stresses for $N_{e l e}=6$ and 8 . For $N_{e l e}=4$, the difference in average ultimate compressive stresses reaches $4.8 \%$.

\subsection{Cross-sectional shapes}

\subsubsection{Unconstrained shapes}

Fig. 9 illustrates the two fittest (Fig. 9 (a, b)) and two least fit (Fig. 9 (c, d)) unconstrained optimised cross-sections (see [5] for reference). The ultimate compressive stress $N_{d} A_{s}$ is used to rank the cross-section from the fittest to the least fit. Closed or nearly closed rounded "bean" shapes are observed. The fittest solution in Fig. 9 (a) has an ultimate compressive stress of $223.2 \mathrm{MPa}$, a cross-sectional depth of $108.3 \mathrm{~mm}$, a width of $61.1 \mathrm{~mm}$, and therefore a depth-to-width ratio of 1.8 .

\subsubsection{Case I shapes}

Fig. 10 to Fig. 12 show the optimised cross-sections for assembly Case I (only horizontal flange) and all investigated number of elements $N_{\text {ele }}$ per half cross-section. The two fittest cross-sections 
(subscript $(a, b))$ and two least fit ones (subscript $(c, d)$ ) for each number of elements $N_{\text {ele }}$ are presented in these figures. "Sigma" or "Cee" type shapes are found, with the cross-section being open for $N_{\text {ele }}=4$ and closed up when $N_{\text {ele }}$ increases to 8 . As $N_{e l e}$ increases from 4 (Fig. 10) to 8 (Fig. 12), the shape of the two fittest cross-sections tends to approach the unconstrained ones (Fig. 9). The fittest cross-section when $N_{\text {ele }}=8$ in Fig. 12(a) has a depth of $100.8 \mathrm{~mm}$, a width of $60.6 \mathrm{~mm}$ and therefore a depth-to-width ratio of 1.7 . It is therefore slightly shallower $(6.9 \%)$ than the unconstrained solution in Fig. 9(a), while being of a similar width (within $0.7 \%$ ).

For all values of $N_{\text {ele }}$, the algorithm tends to have a horizontal flange about $25 \mathrm{~mm}$ to $35 \mathrm{~mm}$ long and to curve the cross-section next to the horizontal flange with a nearly uniform curvature radius (subscript (a, b) in Fig. 10 to Fig. 12) to resist flexural-torsional and distortional buckling. The web is typically composed of two (subscript (a, b) in Fig. 10 and Fig. 11) or three (Fig. $12(a, b)$ ) segments (per entire section) forming a long web stiffener about $35 \mathrm{~mm}$ to $55 \mathrm{~mm}$ long located at the first or second element (per half section), to enhance the local buckling resistance of the overall web.

\subsubsection{Case II shapes}

Fig. 13 to Fig. 15 illustrate the optimised cross-sections for assembly Case II (horizontal flange and vertical web). Similar to Case I, open "Sigma" type shapes for $N_{e l e}=4$ (Fig. 13) and closed or nearly closed "Sigma" type shapes are observed for $N_{e l e}=6$ (Fig. 14) and $N_{\text {ele }}=8$ (Fig. 15). The vertical web and horizontal flange for $N_{e l e}=4$ (Fig. 13) and 6 (Fig. 14) are consecutive and forms a "rightangle" bend. As the vertical web is positioned at the second element number, an odd number of manufacturing bends is observed for these cross-sections. For $N_{e l e}=8$ in Fig. 15 , as the vertical web is located at the first element and an even number of manufacturing bends is required for these cross-sections.

The cross-sectional shape of the fittest solution for $N_{\text {ele }}=8$ in Fig. 15 (a) is similar to the one for assembly Case I (Fig. 12 (a)), for which a vertical web was generated by the algorithm, despite not 
being part of the constraints. Similar to assembly Case I, for the two fittest cross-sections when $N_{\text {ele }}$ $=6($ Fig. $14(\mathrm{a}, \mathrm{b}))$ and 8 (Fig. $15(\mathrm{a}, \mathrm{b}))$, the algorithm tends to curve the elements next to the flange and to create a large web stiffener.

For $N_{e l e}=4$ in Fig. 13, the algorithm generates cross-sections that are on average about $38 \%$ deeper and $16 \%$ wider than those for $N_{\text {ele }}=6$ (Fig. 14) and 8 (Fig. 15). The depth and width of the fittest cross-sections in Fig. 13 (a) is $140.8 \mathrm{~mm}$ and $69.6 \mathrm{~mm}$, respectively, therefore leading to a depth-to-width ratio of 2.0 . Its cross-sectional area is $363.9 \mathrm{~mm}^{2}$, which is $7.6 \%$ and $6.2 \%$ larger than the one of the fittest cross-section for $N_{e l e}=8$ in Fig. 15 (a) (assembly Case II) and $N_{\text {ele }}=4$ in Fig. 10 (a) (assembly Case I), respectively. To satisfy the strength criteria with the small number of elements $\left(N_{e l e}=4\right)$ and the two fastening elements, the algorithm tends to enlarge and open the cross-section when compared to $N_{\text {ele }}=8$ for Case II and $N_{\text {ele }}=4$ for Case I.

Again for $N_{e l e}=4$ in Fig. 13, the sections have a relatively long horizontal flange (approximately 50 $\mathrm{mm}$ to $55 \mathrm{~mm}$ long), when compared to $N_{\text {ele }}=6$ (Fig. 14) and 8 (Fig. 15), to resist lateral and flexural-torsional buckling by increasing the second moment of area about the axis perpendicular to the axis of symmetry. The sections also have a short lip stiffener (approximately $20 \mathrm{~mm}$ to $25 \mathrm{~mm}$ long), oriented at approximately $45^{\circ}$ to the horizontal flange, to resist distortional buckling. On the other hand, similar to assembly Case I, a long web stiffener, oriented at approximately $20^{\circ}$ to the vertical web, allows deep cross-sections by improving the local buckling resistance of the web. Due to the large open cross-section for $N_{e l e}=4$, the utility constraint (set in assembly Case III) is satisfied. The $y$-coordinate of the last cross-sectional point of all cross-sections in Fig. 13 is greater than the minimum utility clearance distance $D_{\min }=30 \mathrm{~mm} . N_{e l e}=4$ for assembly Case III is therefore not run and results from $N_{\text {ele }}=4$ for assembly Case II are used in the following Sections. 


\subsubsection{Case III shapes}

Fig. 16 and Fig. 17 represent the two fittest $(a, b)$ and two least fit (c, d) optimised cross-sections for $N_{e l e}=6$ and 8, respectively, for assembly Case III. Open "Sigma" type cross-sectional shapes are typically observed. The fittest solutions for $N_{\text {ele }}=6$ and 8 have utility distances of $30.6 \mathrm{~mm}$ (Fig. 16 (a)) and $29.4 \mathrm{~mm}$ (Fig. 17 (a)), respectively. These distances are close (within $2 \%$ ) to the minimum utility clearance $D_{\min }$ of $30 \mathrm{~mm}$ set per half cross-section (see Section 2.2.2). Similar to all previous assembly cases, except for $N_{\text {ele }}=4$ in Case II, the algorithm tends to have a short horizontal flange, curve elements next to the flange and large web stiffener. The fittest cross-section for $N_{\text {ele }}=8$ in Fig. 17 (a) has an ultimate compressive stress of $218.3 \mathrm{MPa}$. It is $118.8 \mathrm{~mm}$ deep and $67.7 \mathrm{~mm}$ wide, which is $8.8 \%$ deeper and $9.8 \%$ wider than the fittest unconstrained cross-section in Fig. 9 (a). Its depth-to-width ratio is 1.8 . It is worth mentioning that while the vertical web is located at the first element in Fig. 17 (a), the third element is also vertical and forms a "right-angle" bend with the horizontal flange, creating the overall web stiffener.

\subsection{Capacity improvement}

The average nominal member capacity in compression of the constrained optimised solutions in Table 4 to Table 6 is compared to the capacity of conventional lipped channels that have similar aspect ratios to the cross-sections manufactured by Bluescope Lysaght [16] in Australia. These conventional lipped channels satisfy the geometric limitations for compression members for design using the Direct Strength Method given in Table 7.1.1 of the Australian Standard AS4600 [19]. The conventional cross-sections have a wall thickness of $1.2 \mathrm{~mm}$ (same as the optimised crosssections) and are designed with a cross-sectional area equal to the ones of the optimised solutions for $N_{\text {ele }}=4$ in Tables 4 and 6 . Table 7 summarises the comparison between the conventional crosssections and the optimised ones for each assembly case. The nominal member capacity of the optimised solutions is significantly higher (up to $116 \%$ and no less than $101 \%$ ) than the conventional cross-sections. 


\section{CONCLUSIONS}

This paper has introduced manufacturing and assembly features into a shape optimisation algorithm for CFS columns. The principles of the algorithm have been explained and applied to simplysupported singly-symmetry, free to warp open section columns. The major findings are:

- The robustness of the algorithm was verified by having consistent optimised solutions with a maximum CoV of $0.49 \%\left(N_{e l e}=8\right.$ in Case I $)$ and $0.54 \%\left(N_{e l e}=4\right.$ in Cases II and III $)$ for the cross-sectional area and the member capacity, respectively, over 10 runs.

- The algorithm converged rapidly in 50 to 60 generations to an optimised solution, and 500 individuals and 80 generations (40,000 solutions) are found adequate for convergence.

- The more the cross-sectional elements, the less the cross-section area is. Moreover, when the number of cross-sectional elements increases, the cross-section tends to close. Specifically, a small number of elements $\left(N_{\text {ele }}=4\right)$ with a horizontal flange and a vertical web resulted in (i) largely open "Sigma" type cross-sectional shapes, (ii) long horizontal flange and web stiffener and (iii) lip stiffener oriented at 45 degree to the horizontal flange. A large number of elements $\left(N_{e l e}=8\right)$, on the other hand, resulted in (i) closed "Sigma" type crosssectional shapes, (ii) short horizontal flange and long web stiffener and (iii) curved elements next to the flange.

- When the utility constraint was considered (assembly Case III) with a large number of crosssectional elements $\left(N_{\text {ele }}=8\right)$, the algorithm tended to close the cross-section to its maximum while satisfying the minimum utility clearance. The curved cross-sectional shape next to the flange was also present.

- The optimised manufacturable and usable cross-sections are only up to $7 \%$ less efficient than the optimised unconstrained ones. The optimised solutions exhibit a member capacity in compression more than twice that of the conventional lipped Cee-sections of a similar crosssection area. 


\section{REFERENCES}

[1] Hancock GJ, Design of cold-formed steel structures (to AS/NZ 4600:2007) - 4th Edition, Australian Steel Institute, North Sydney, Australia, 2007.

[2] Liu H, Igusa T, Schafer B "Knowledge-based global optimization of cold-formed steel columns", Thin-Walled Structures, 42, 785-801, 2004.

[3] Leng J, Guest JK, Schafer BW "Shape optimization of cold-formed steel columns", ThinWalled Structures, 49, 1492-1503, 2011.

[4] Gilbert BP, Teh LH, Guan H "Self-shape optimisation principles: Optimisation of section capacity for thin-walled profiles", Thin-Walled Structures, 60, 194-204, 2012a.

[5] Gilbert BP, Savoyat TJM, Teh LH "Self-shape optimisation application: Optimisation of coldformed steel columns", Thin-Walled Structures, 60, 173-184, 2012b.

[6] Moharrami M, Louhghalam A, Tootkaboni M "Optimal folding of cold formed steel cross sections under compression", Thin-Walled Structures, 76, 145-156, 2014.

[7] Madeira JFA, Dias J, Silvestre N "Multiobjective optimization of cold-formed steel columns", Thin-Walled Structures, 96, 29-38, 2015.

[8] Wang B, Bosco GL, Gilbert BP, Guan H, Teh LH "Unconstrained shape optimisation of singly-symmetric and open cold-formed steel beams and beam-columns", Thin-Walled Structures, 104, 54-61, 2016.

[9] Leng J, Li Z, Guest JK, Schafer BW, "Shape optimization of cold-formed steel columns with manufacturing constraints and limited number of rollers", Proceedings of the Structural Stability Research Council Annual Stability Conference, 313-331, 2013.

[10] Wang B, Gilbert BP, Molinier AM, Guan H, Teh LH "Shape optimisation of cold-formed steel columns with manufacturing constraints using the Hough transform", Thin-Walled Structures, 106, 75-92, 2016. 
[11] Wang B, Gilbert BP, Guan H, Teh LH, "Shape optimisation of manufacturable cold-formed steel columns for all buckling modes - Part II: Improved method", Proceedings of the Eight International Conference on Advances in Steel Structures, Lisbon, Portugal, 2015.

[12] Franco JMS, Duarte JP, Batista EdM, Landesmann A "Shape Grammar of steel cold-formed sections based on manufacturing rules", Thin-Walled Structures, 79, 218-232, 2014.

[13] Leng J, Li Z, Guest JK, Schafer BW, "Constrained shape optimization of cold-formed steel columns", Proceedings of the 21st International Specialty Conference on Cold-Formed Steel Structures, St. Louis, MO; United States, 59-73, 2012.

[14] Leng J, Li Z, Guest JK, Schafer BW "Shape optimization of cold-formed steel columns with fabrication and geometric end-use constraints", Thin-Walled Structures, 85, 271-290, 2014.

[15] Adeli H, Sarma KC, Evolutionary Computing and the Genetic Algorithm, in: Cost Optimization of Structures, John Wiley \& Sons, Ltd, 2006, pp. 37-52.

[16] The Lysaght Referee - 32nd Edition, BlueScope Steel Limited, NSW, Australia, 2009.

[17] Gilbert BP, Teh LH, Guan H, Self-shape optimisation of cold-formed steel closed profiles using Genetic Algorithm, Research Report CIEM/2011/R01, 2011.

[18] Schafer BW "Review: the direct strength method of cold-formed steel member design", Journal of Constructional Steel Research, 64, 766-778, 2008.

[19] AS/NZS 4600, Cold-formed steel structures, Standards Australia, Sydney, 2005.

[20] Schafer B, Ádány S, "Buckling analysis of cold-formed steel members using CUFSM: conventional and constrained finite strip methods", Proceedings of the Eighteenth international specialty conference on cold-formed steel structures (Eds.: R.A. LaBoube, W.W. Yu), St. Louis, Missouri, USA, 39-54, 2006.

[21] Adeli H, Cheng N "Augmented Lagrangian Genetic Algorithm for Structural Optimization", Journal of Aerospace Engineering, 7, 104-118, 1994. 


\section{FIGURES}

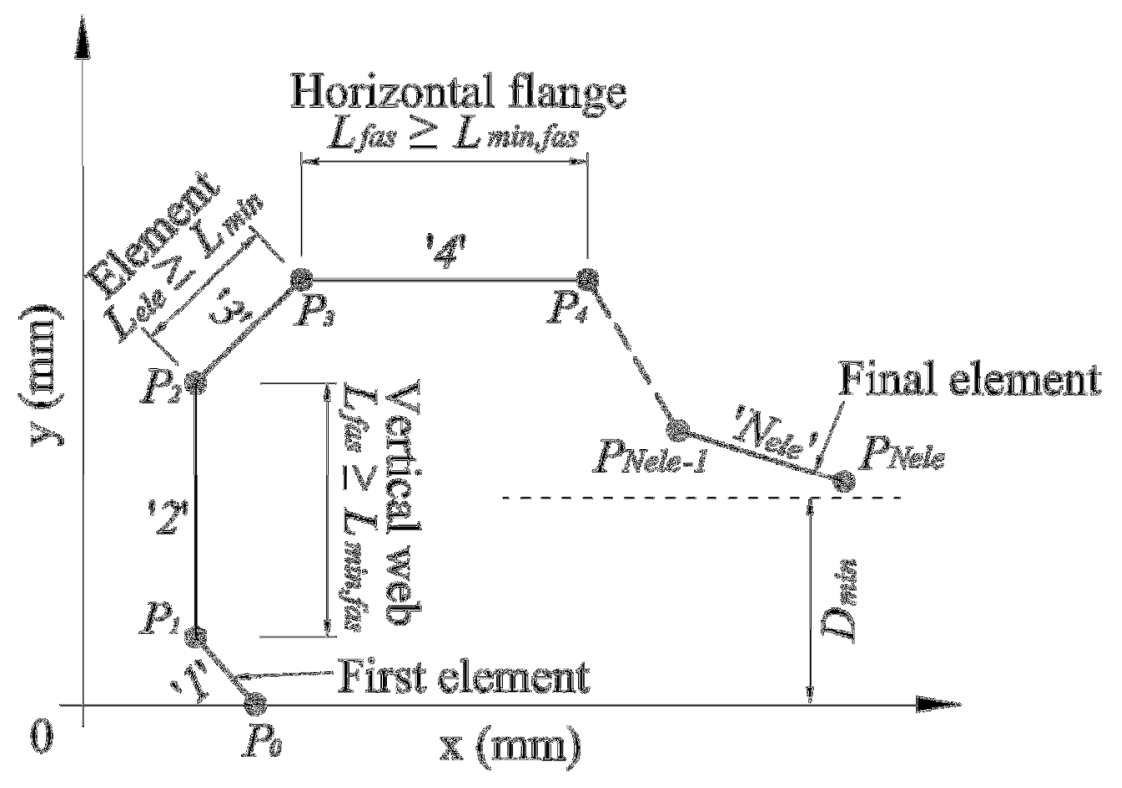

Fig. 1: Assembly constraints per half cross-section with the vertical web shown for the second element and the horizontal flange for the fourth element

Range for $\theta$ :

$+45^{\circ}$ to $-45^{\circ}$ to the vertical

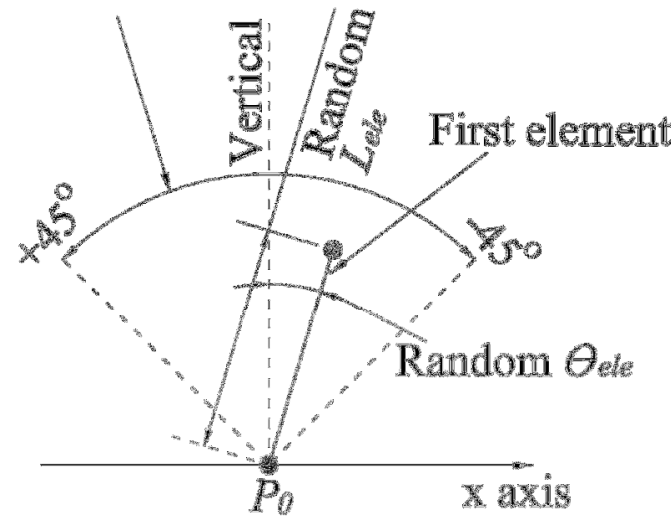

(a) First element
Range for $\theta$ :

$+45^{\circ}$ to $-45^{\circ}$ to the direction of the last built element

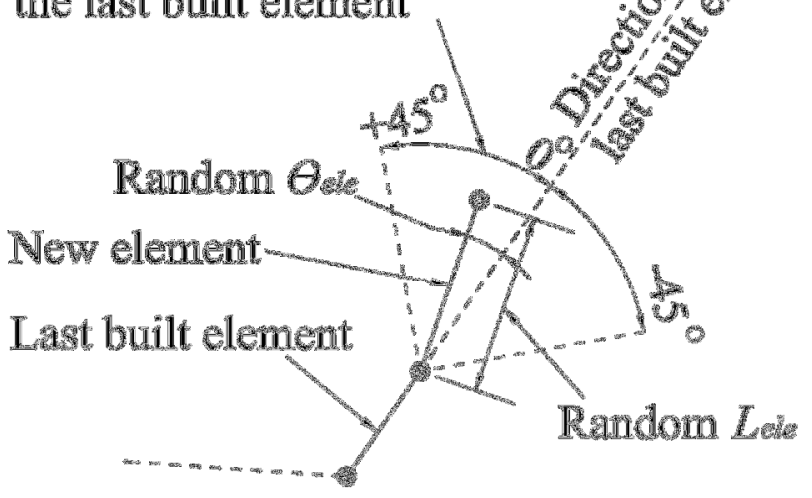

(b) New element

Fig. 2: Creating an initial half cross-section 


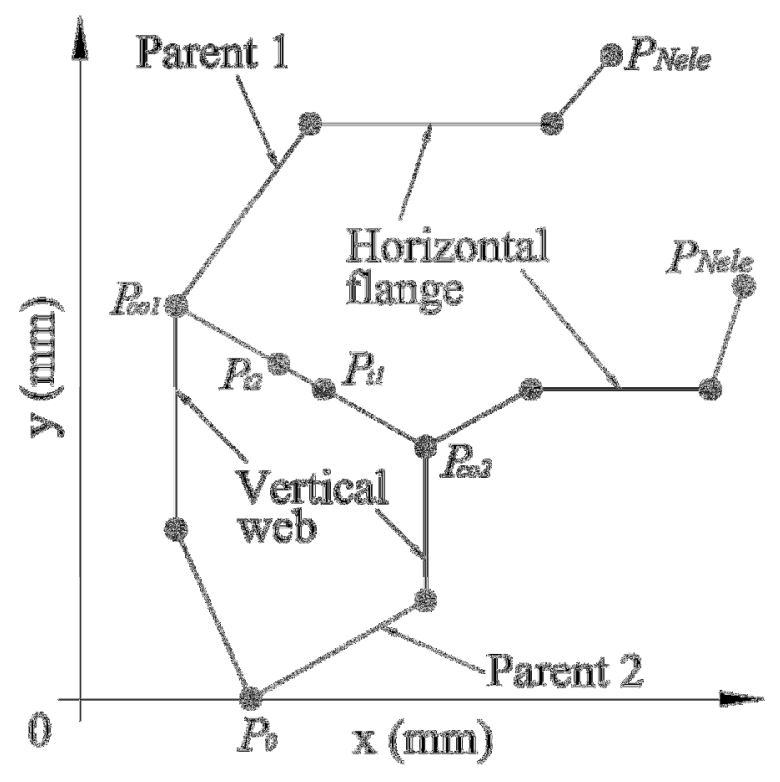

(a) Select cross-over points $P_{t 1}$ and $P_{t 2}$

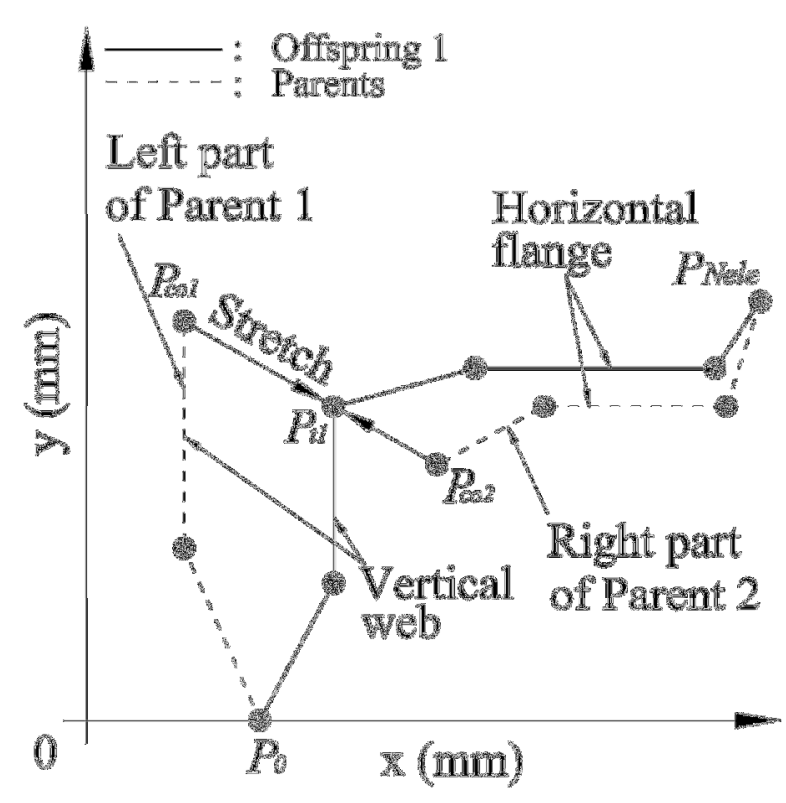

(b) First offspring

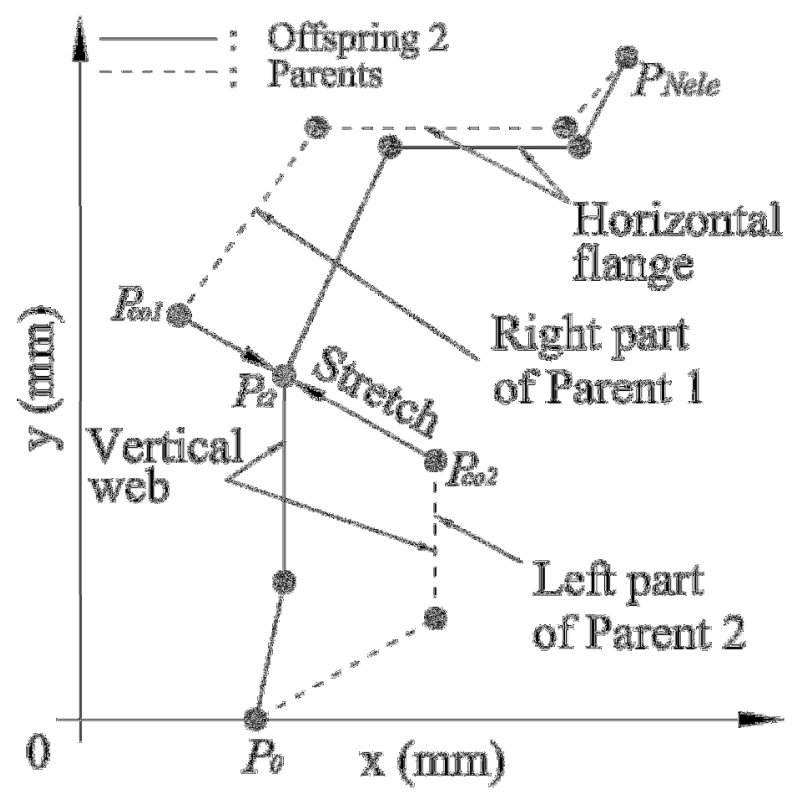

(c) Second offspring

Fig. 3. Cross-over operator, illustrated with cross-sections (five segments per half section) 


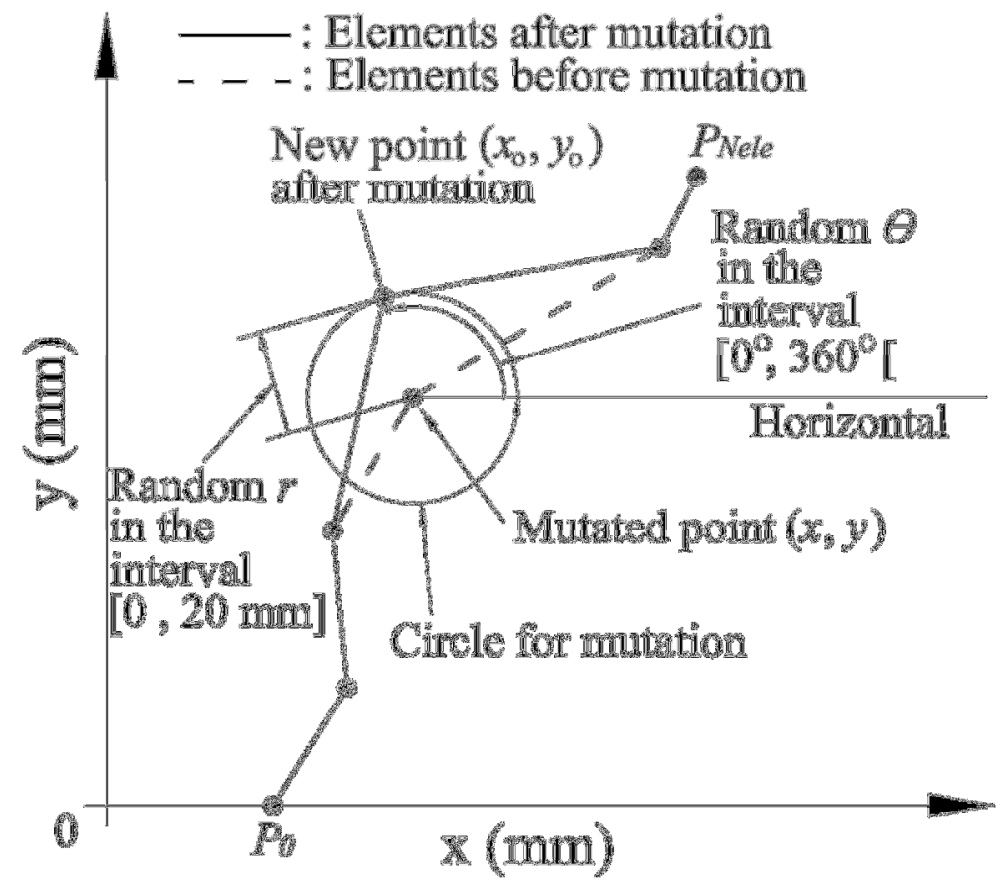

Fig. 4. Mutation operator

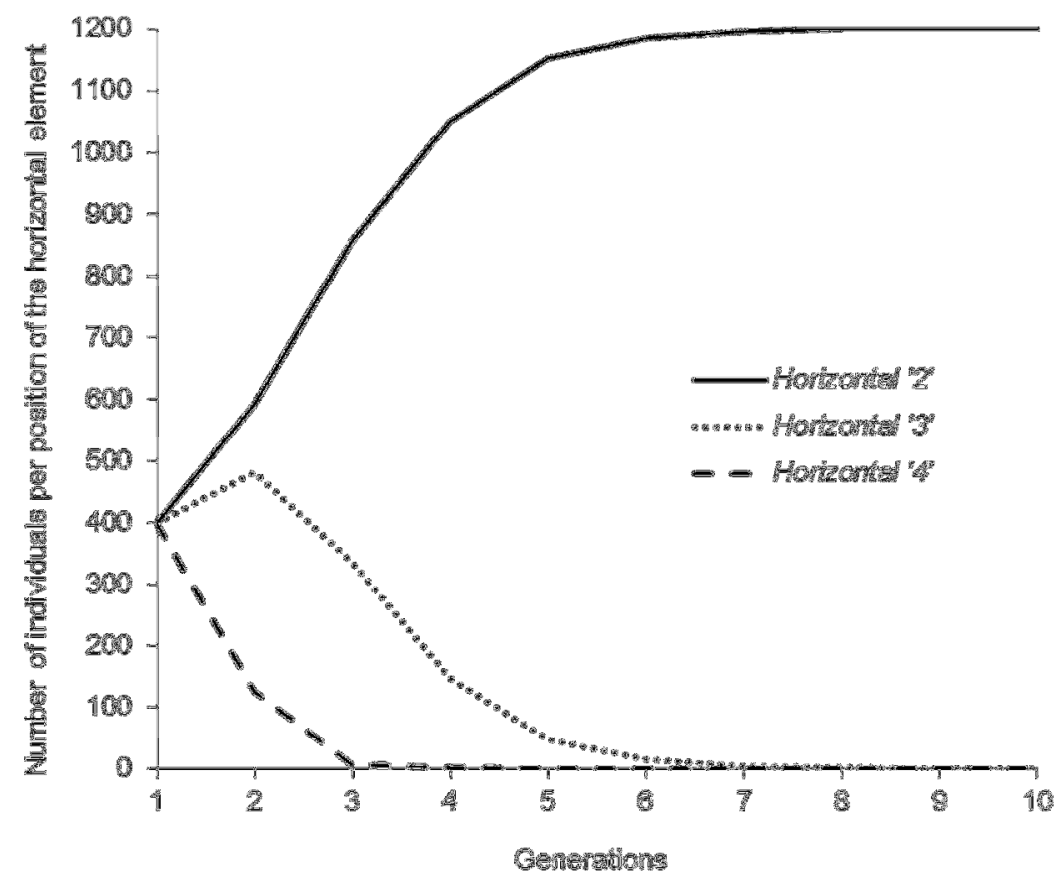

Fig. 5: Number of individuals per possible locations of the fastening element, shown for $N_{\text {ele }}=4$ and Case I 


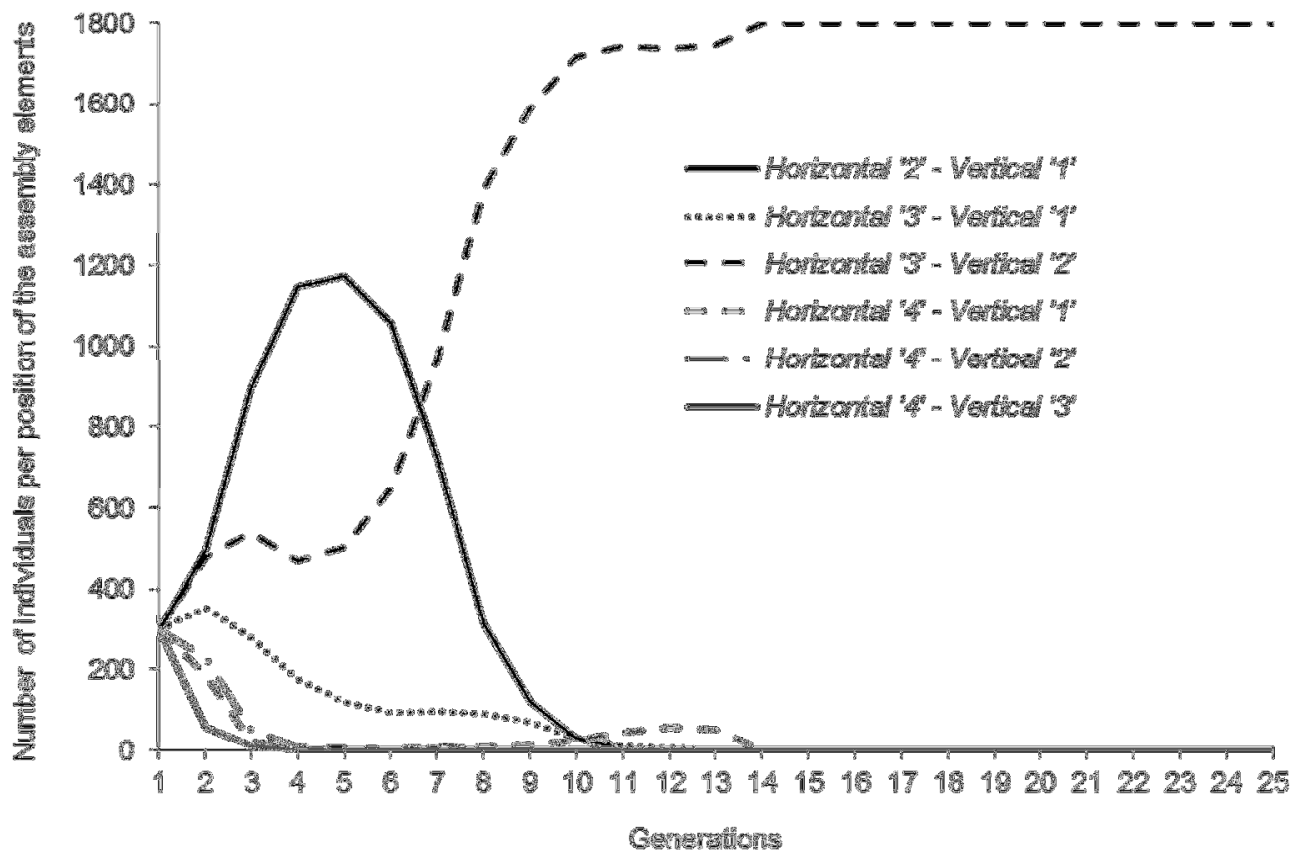

Fig. 6: Number of individuals per possible locations of the fastening elements, shown for $N_{\text {ele }}=4$ and Case II

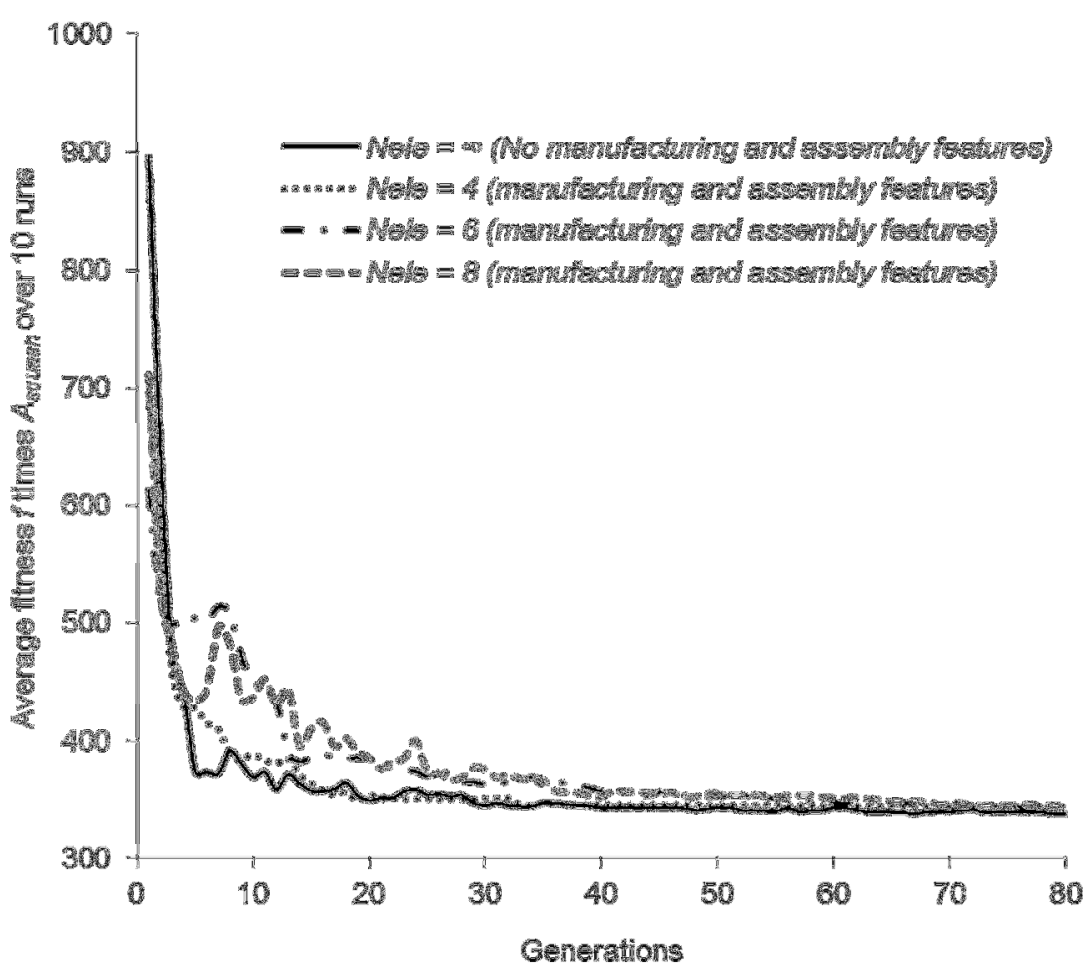

(a) 


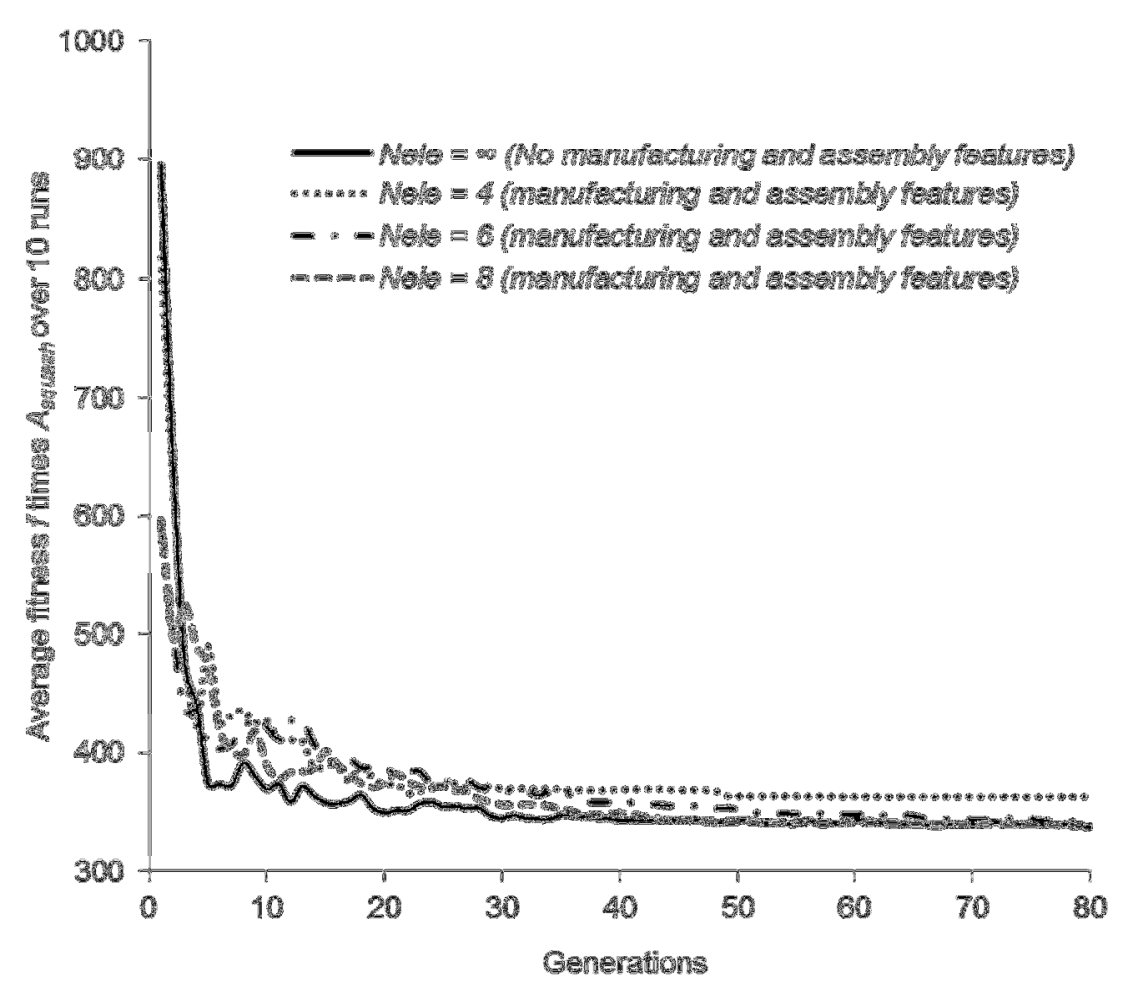

(b)

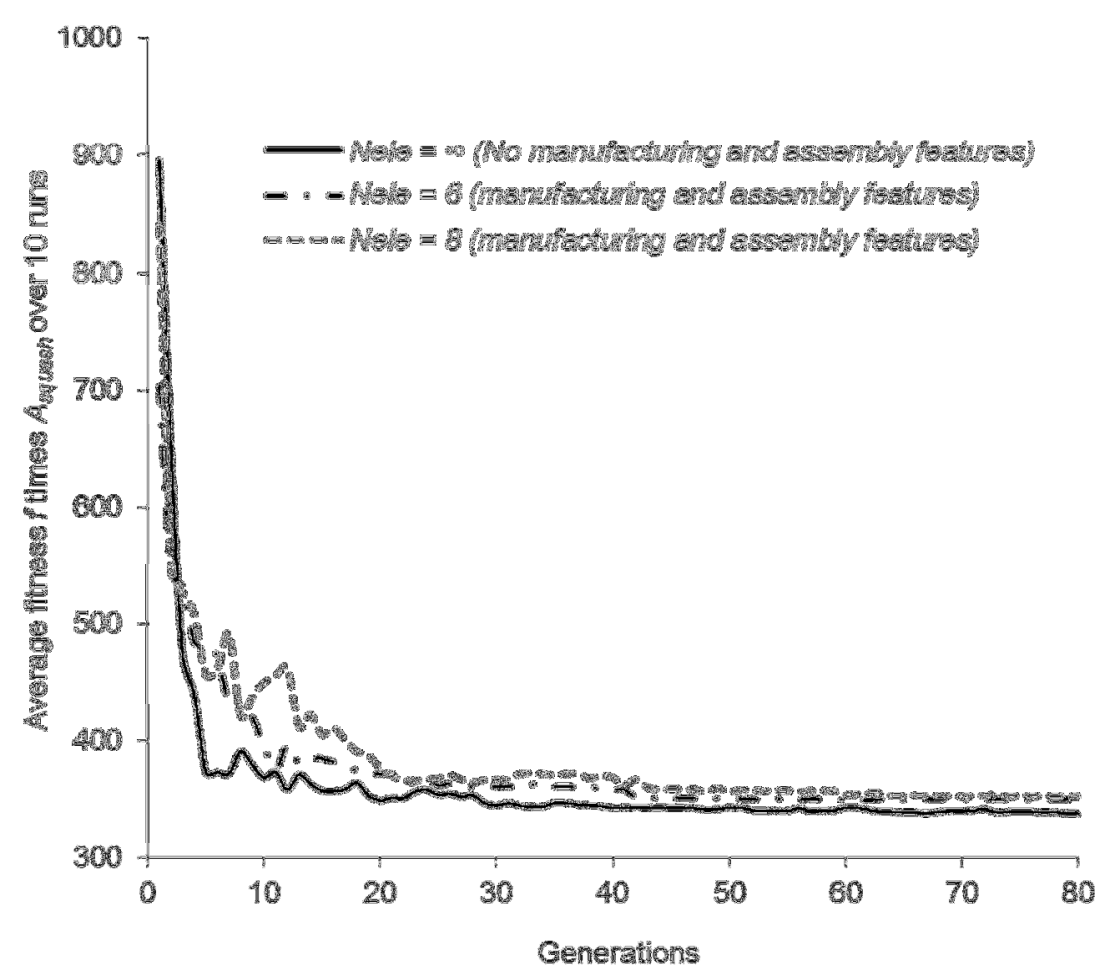

(c)

Fig. 7: Convergence for assembly (a) Case I, (b) Case II and (c) Case III (see [5] for reference of no manufacturing and assembly features) 


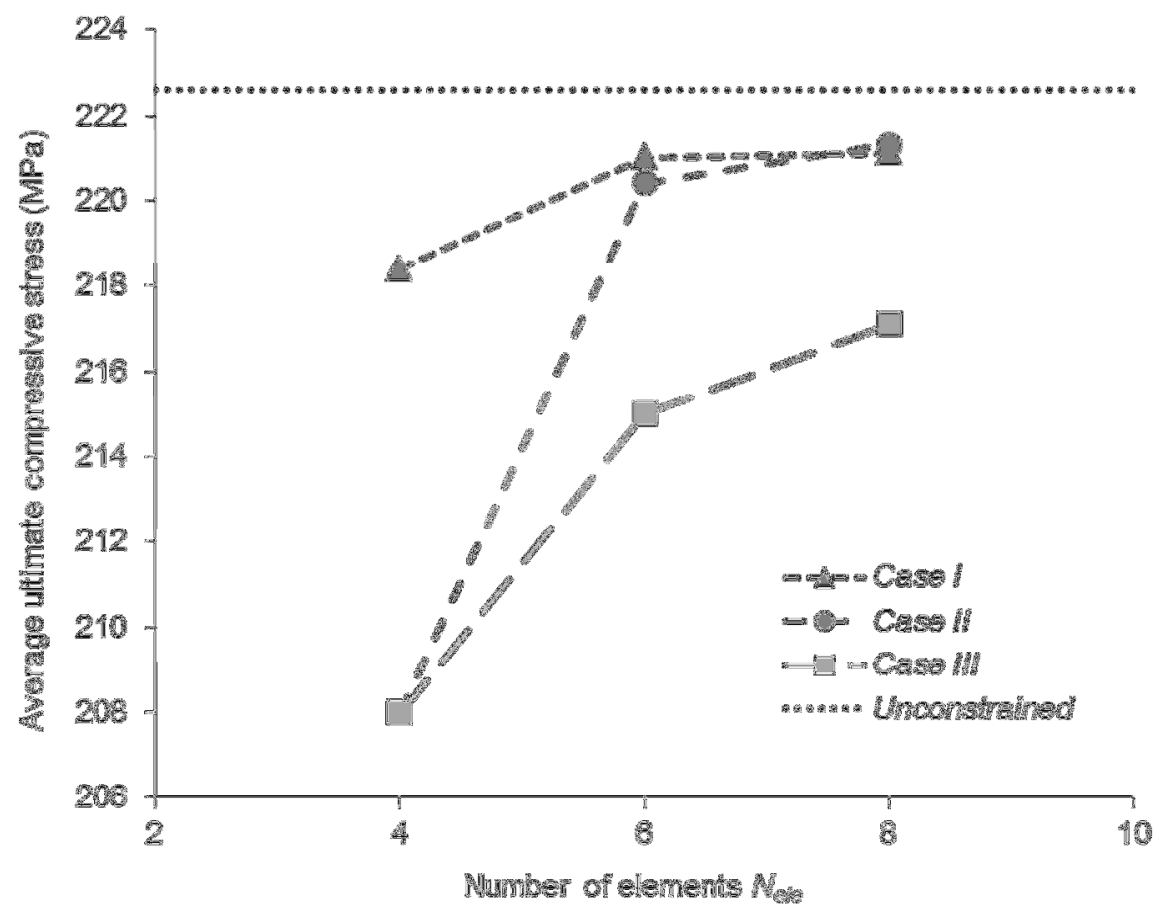

Fig. 8: Average ultimate compressive stress for all the cases investigated

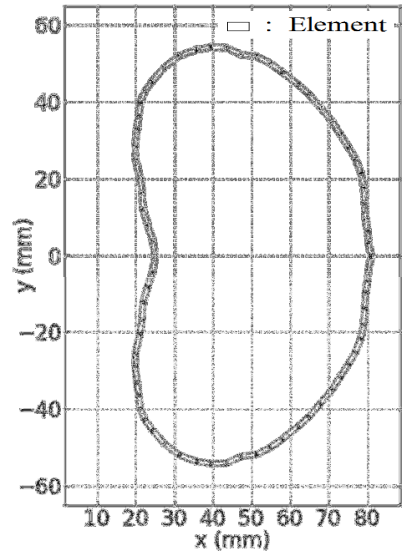

(a) $A_{s}=336.5 \mathrm{~mm}^{2}$ $N_{c}=75.1 \mathrm{kN}$ $N_{d} / A_{s}=223.2 \mathrm{MPa}$

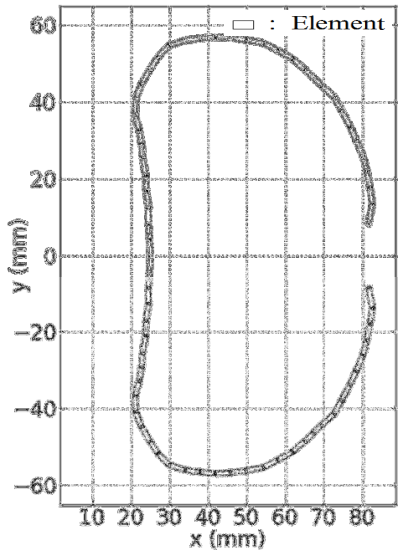

(b) $A_{s}=338.0 \mathrm{~mm}^{2}$ $N_{c}=75.4 \mathrm{kN}$ $N_{d} / A_{s}=223.1 \mathrm{MPa}$
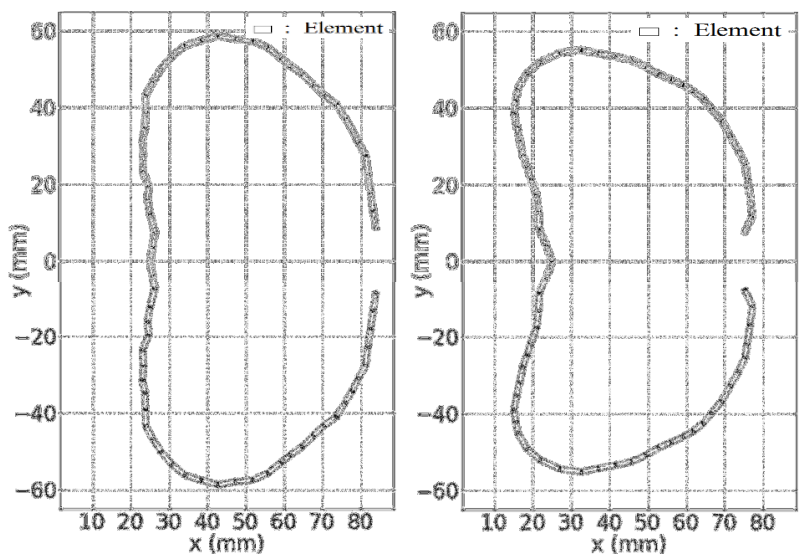

(c) $\begin{aligned} & A_{s}=338.3 \mathrm{~mm}^{2} \\ & N_{c}=75.0 \mathrm{kN} \\ & N_{d} d A_{s}=221.7 \mathrm{MPa}\end{aligned}$ (d) $A_{s}=339.0 \mathrm{~mm}^{2}$ $N_{c}=75.1 \mathrm{kN}$ $N_{d} / A_{s}=221.5 \mathrm{MPa}$

Fig. 9: Optimised cross-sections of unconstrained algorithm (see [5] for reference), (a, b) fittest cross-sections and (c, d) least fit cross-sections 


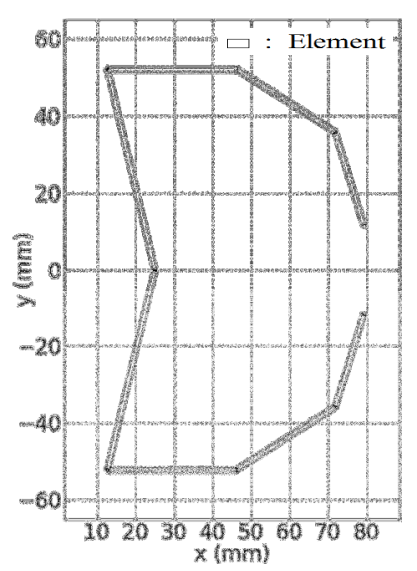

(a) $A_{s}=342.7 \mathrm{~mm}^{2}$

$N_{c}=75.5 \mathrm{kN}$

$N_{d} / A_{s}=220.3 \mathrm{MPa}$

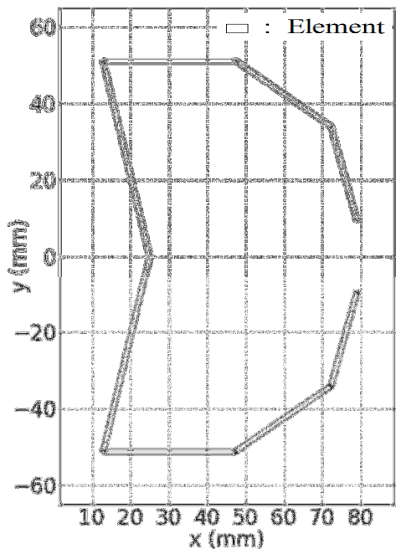

(b) $A_{s}=342.5 \mathrm{~mm}^{2}$ $N_{c}=75.3 \mathrm{kN}$ $N_{d} A_{s}=219.9 \mathrm{MPa}$
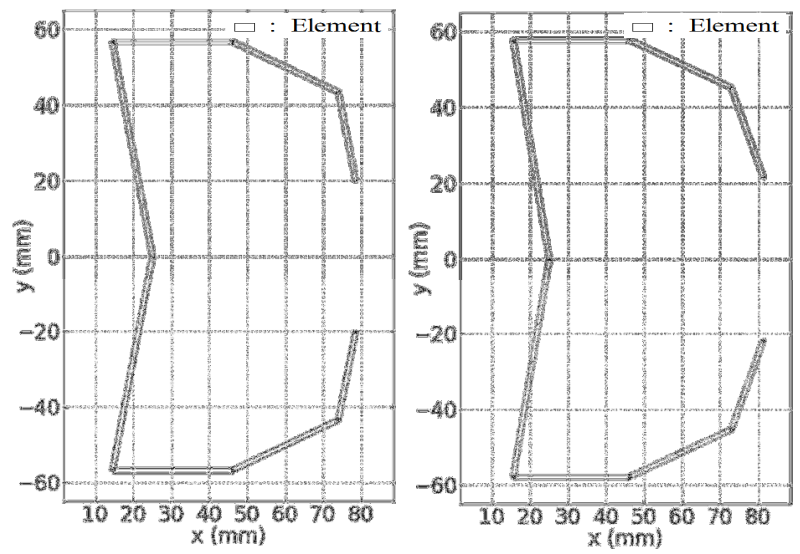

(c) $\begin{aligned} & A_{s}=345.6 \mathrm{~mm}^{2} \\ & N_{c}=75.2 \mathrm{kN} \\ & N_{d} A_{s}=217.6 \mathrm{MPa}\end{aligned}$ (d) $A_{s}=345.0 \mathrm{~mm}^{2}$

$N_{c}=75.0 \mathrm{kN}$

$N_{d} A_{s}=217.4 \mathrm{MPa}$

Fig. 10: Optimised cross-sections for assembly Case I and $N_{\text {ele }}=4,(\mathrm{a}, \mathrm{b})$ fittest cross-sections and (c, d) least fit cross-sections

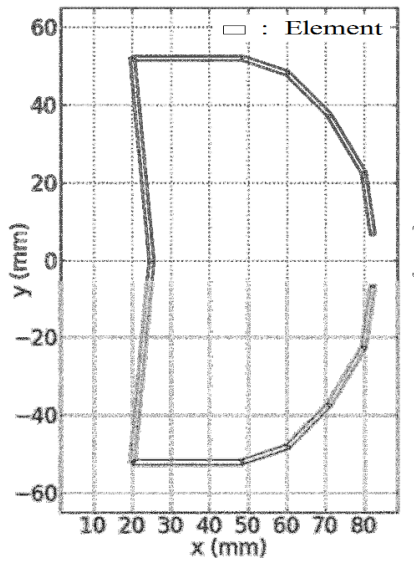
(a) $A_{s}=338.5 \mathrm{~mm}^{2}$
$N_{c}=75.1 \mathrm{kN}$
$N_{d} / A_{s}=221.9 \mathrm{MPa}$

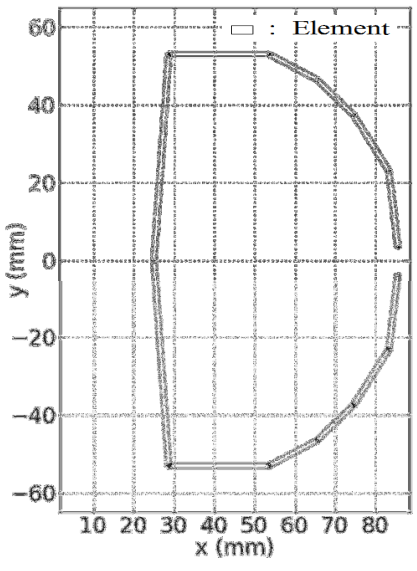

(b) $\begin{aligned} A_{s} & =339.8 \mathrm{~mm}^{2} \\ N_{c} & =75.3 \mathrm{kN} \\ N_{d} & A_{s}=221.6 \mathrm{MPa}\end{aligned}$
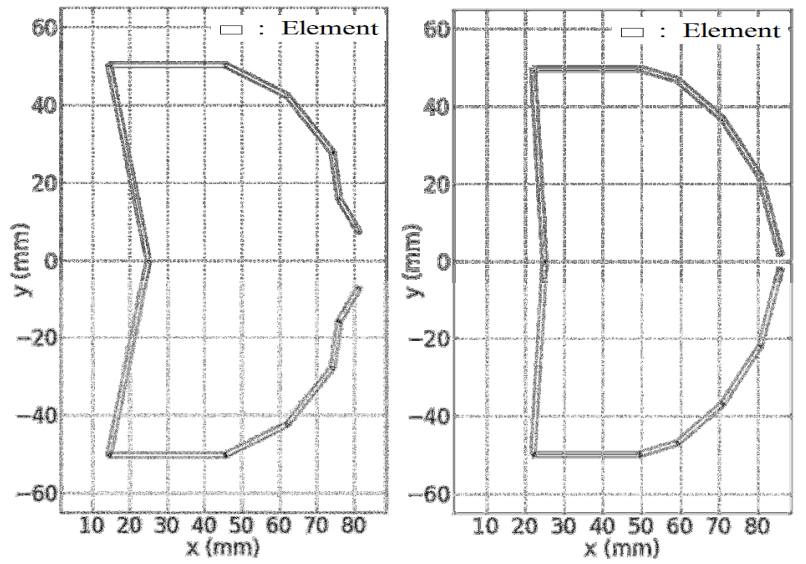
(c) $A_{s}=340.4 \mathrm{~mm}^{2}$ $N_{c}=75.0 \mathrm{kN}$ $N_{d} / A_{s}=220.3 \mathrm{MPa}$

Fig. 11: Optimised cross-sections for assembly Case I and $N_{e l e}=6,(a, b)$ fittest cross-sections and (c, d) least fit cross-sections 


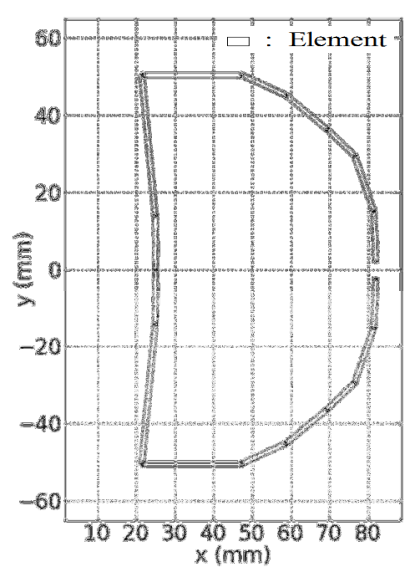

(a) $A_{s}=338.2 \mathrm{~mm}^{2}$

$N_{c}=75.1 \mathrm{kN}$

$N_{d} A_{s}=222.1 \mathrm{MPa}$

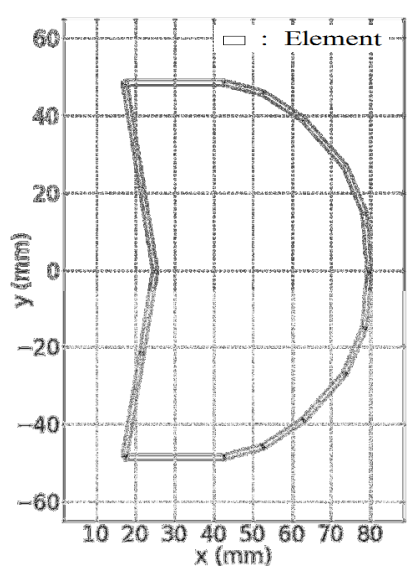

(b) $A_{s}=338.1 \mathrm{~mm}^{2}$ $N_{c}=74.9 \mathrm{kN}$ $N_{d} A_{s}=221.5 \mathrm{MPa}$
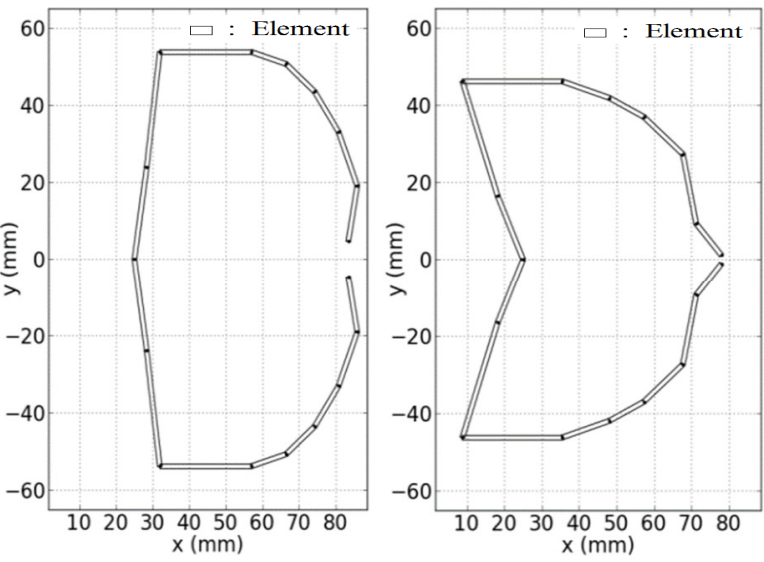

(c) $\begin{aligned} & A_{s}=340.0 \mathrm{~mm}^{2} \\ & N_{c}=74.9 \mathrm{kN} \\ & N_{d} d A_{s}=220.3 \mathrm{MPa}\end{aligned}$ (d) $A_{s}=342.4 \mathrm{~mm}^{2}$ $N_{c}=75.0 \mathrm{kN}$ $N_{d} / A_{s}=219.0 \mathrm{MPa}$

Fig. 12: Optimised cross-sections for assembly Case I and $N_{\text {ele }}=8,(\mathrm{a}, \mathrm{b})$ fittest cross-sections and (c, d) least fit cross-sections

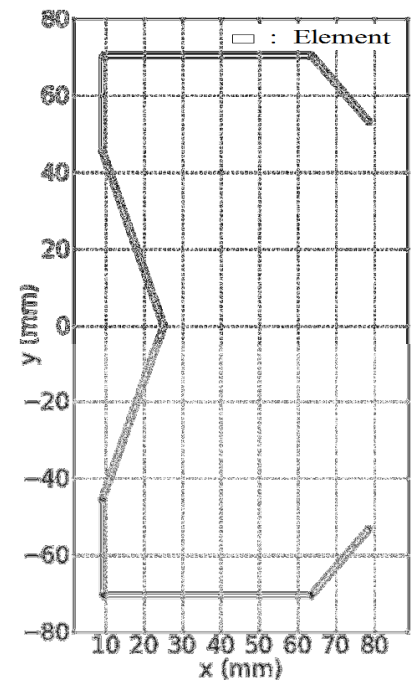

(a) $\begin{aligned} A_{s} & =363.9 \mathrm{~mm}^{2} \\ N_{c} & =76.2 \mathrm{kN} \\ N_{d} A_{s} & =209.4 \mathrm{MPa}\end{aligned}$

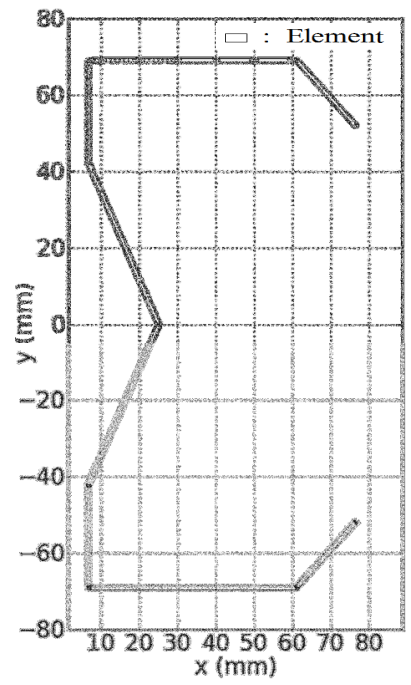

(b) $A_{s}=361.3 \mathrm{~mm}^{2}$ $N_{c}=75.2 \mathrm{kN}$ $N_{d} A_{s}=208.1 \mathrm{MPa}$
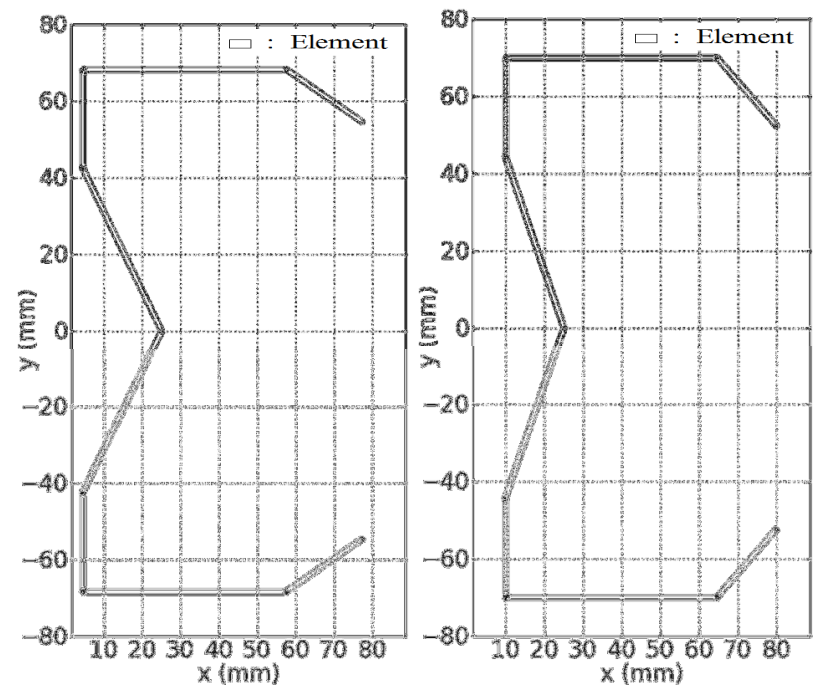
(c) $A_{s}=362.5 \mathrm{~mm}^{2}$ $N_{c}=75.3 \mathrm{kN}$ $N_{d} A_{s}=207.7 \mathrm{MPa}$

Fig. 13: Optimised cross-sections for assembly Case II and $N_{e l e}=4,(\mathrm{a}, \mathrm{b})$ fittest cross-sections and (c, d) least fit cross-sections 


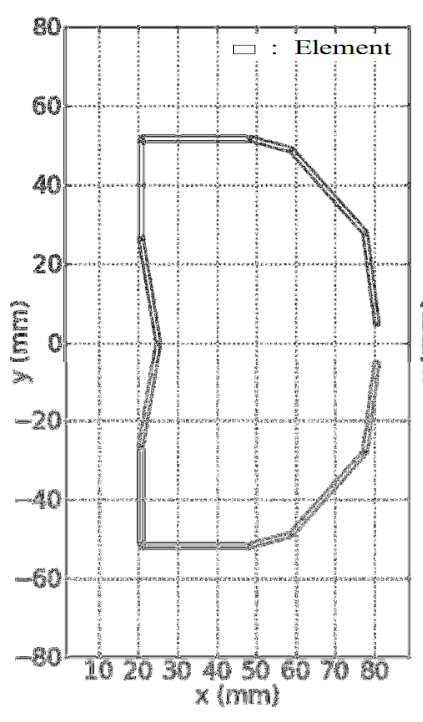

$\begin{array}{ll}\text { (a) } A_{s}=341.0 \mathrm{~mm}^{2} & \text { (b) } A_{s}=339.0 \mathrm{~mm}^{2} \\ N_{c}=75.6 \mathrm{kN} & N_{c}=75.0 \mathrm{kN} \\ N_{d} A_{s}=221.7 \mathrm{MPa} & N_{d} A_{s}=221.2 \mathrm{MPa}\end{array}$
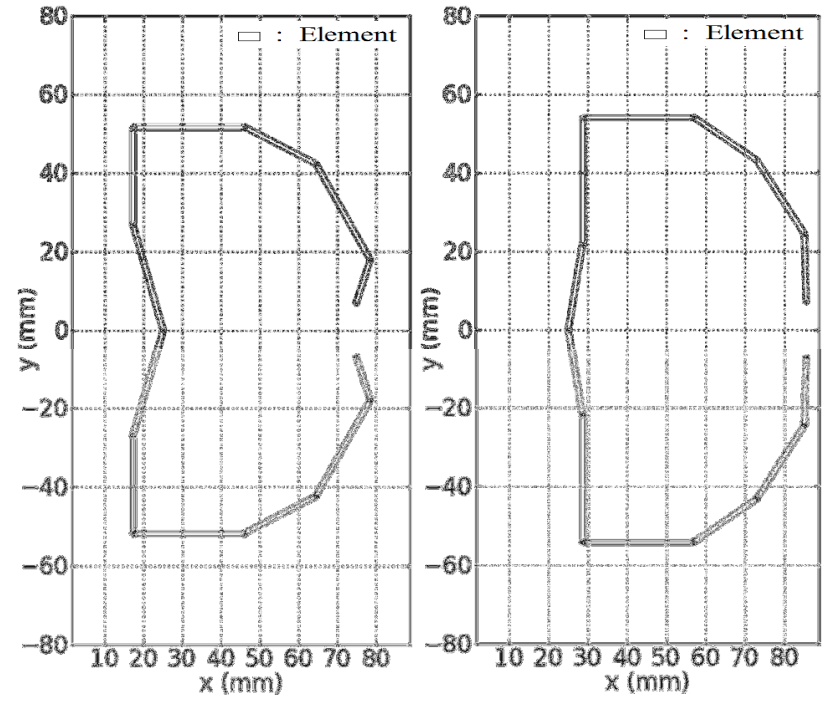

(c) $\begin{aligned} A_{s} & =340.6 \mathrm{~mm}^{2} \\ N_{c} & =74.9 \mathrm{kN} \\ N_{d} & A_{s}=219.9 \mathrm{MPa}\end{aligned}$ (d) $A_{s}=340.7 \mathrm{~mm}^{2}$ $N_{c}=74.8 \mathrm{kN}$ $N_{d} A_{s}=219.5 \mathrm{MPa}$

Fig. 14: Optimised cross-sections for assembly Case II and $N_{e l e}=6,(\mathrm{a}, \mathrm{b})$ fittest cross-sections and (c, d) least fit cross-sections

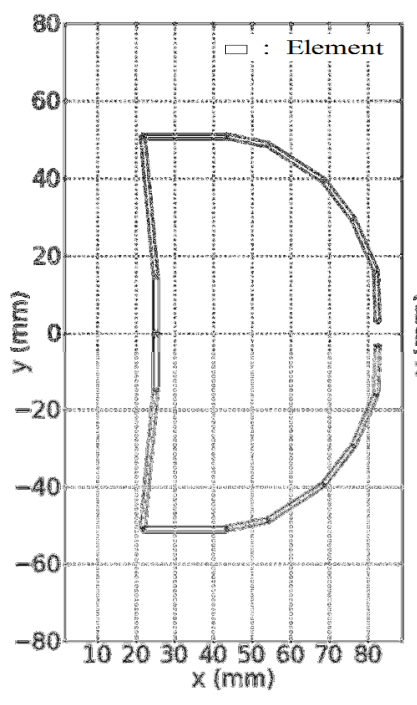

(a) $A_{s}=338.1 \mathrm{~mm}^{2}$

$N_{c}=75.0 \mathrm{kN}$

$N_{d} A_{s}=221.8 \mathrm{MPa}$

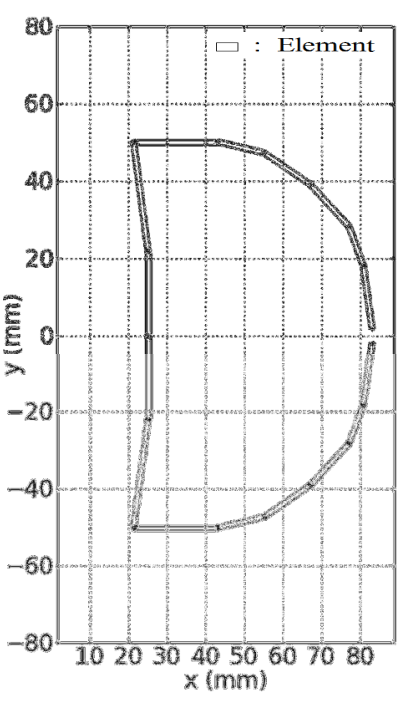

(b) $A_{s}=338.3 \mathrm{~mm}^{2}$ $N_{c}=75.0 \mathrm{kN}$ $N_{C} A_{s}=221.7 \mathrm{MPa}$

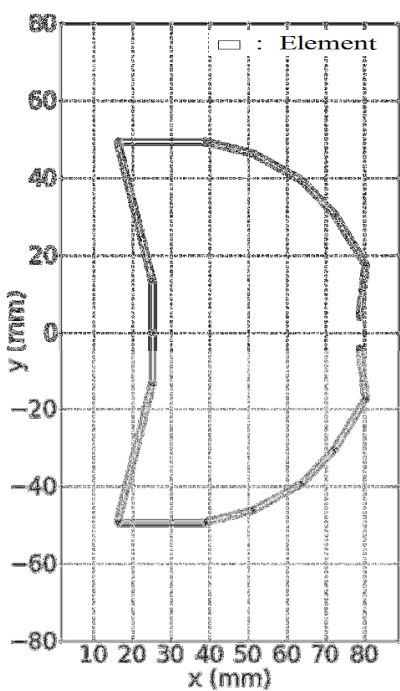

(c) $A_{s}=339.4 \mathrm{~mm}^{2}$ $N_{c}=74.9 \mathrm{kN}$ $N_{C} / A_{s}=220.7 \mathrm{MPa}$

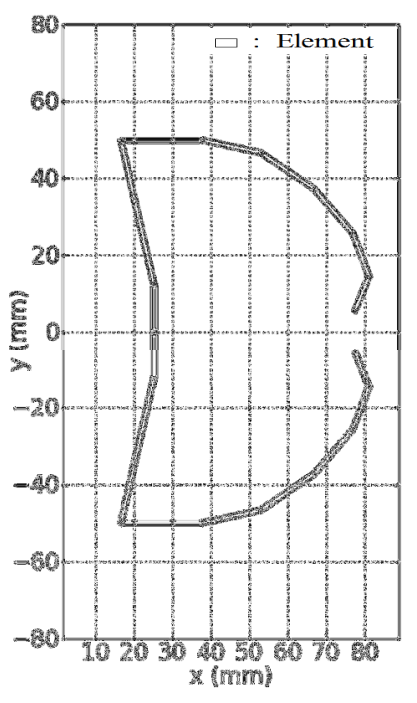

(d) $A_{s}=339.7 \mathrm{~mm}^{2}$ $N_{c}=74.9 \mathrm{kN}$ $N_{C} A_{s}=220.5 \mathrm{MPa}$

Fig. 15: Optimised cross-sections for assembly Case II and $N_{e l e}=8,(a, b)$ fittest cross-sections and (c, d) least fit cross-sections 


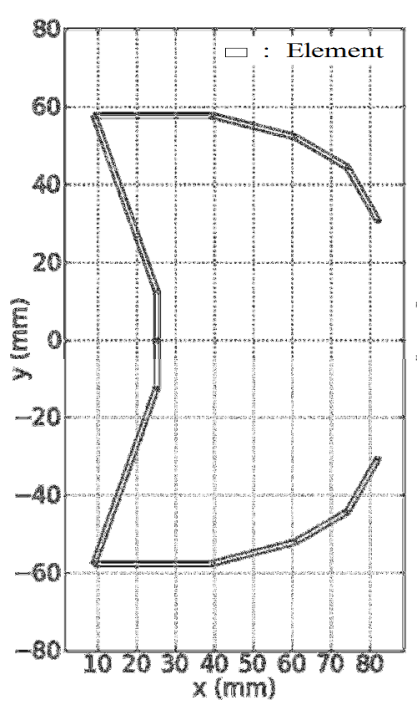

(a) $\begin{aligned} A_{s} & =346.1 \mathrm{~mm}^{2} \\ N_{c} & =75.0 \mathrm{kN} \\ N_{d} & A_{s}=216.7 \mathrm{MPa}\end{aligned}$

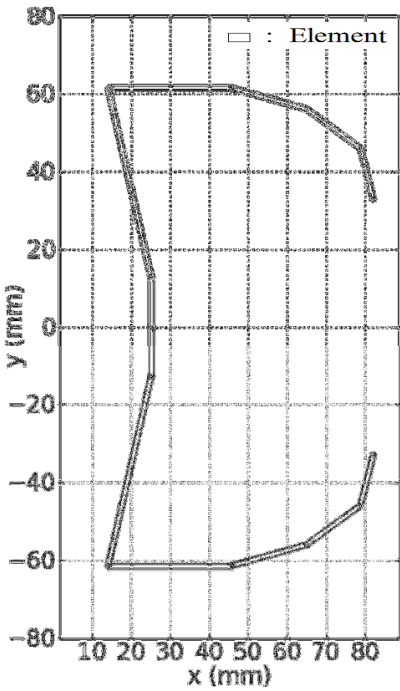

(b) $\begin{aligned} A_{s} & =348.1 \mathrm{~mm}^{2} \\ N_{c} & =75.0 \mathrm{kN} \\ N_{d} A_{s} & =215.5 \mathrm{MPa}\end{aligned}$
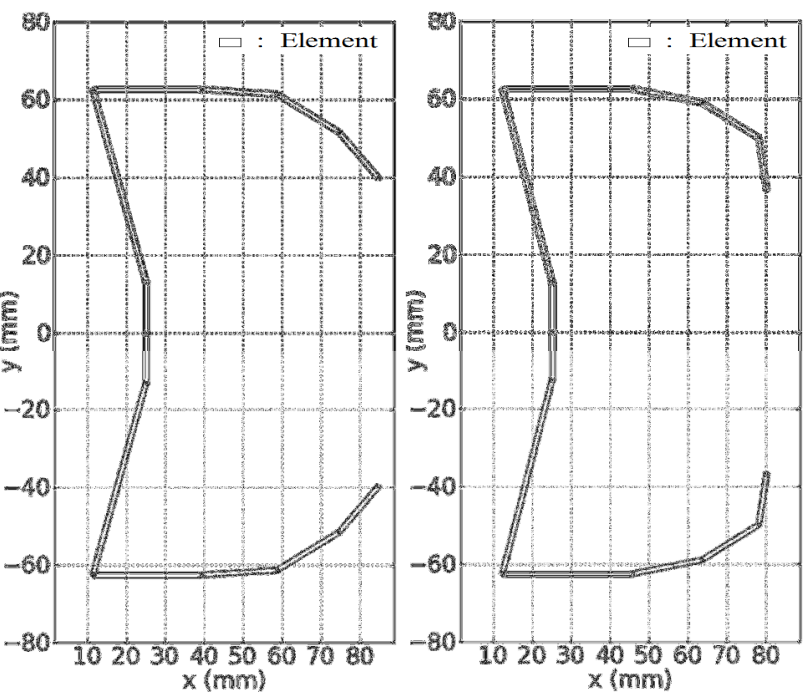

(c) $\begin{aligned} & A_{s}=350.5 \mathrm{~mm}^{2} \\ & N_{c}=74.9 \mathrm{kN} \\ & N_{d} A_{s}=213.7 \mathrm{MPa}\end{aligned}$ (d) $A_{s}=351.0 \mathrm{~mm}^{2}$ $N_{c}=74.9 \mathrm{kN}$ $N_{d} / A_{s}=213.4 \mathrm{MPa}$

Fig. 16: Optimised cross-sections for assembly Case III and $N_{e l e}=6,(\mathrm{a}, \mathrm{b})$ fittest cross-sections and (c, d) least fit cross-sections

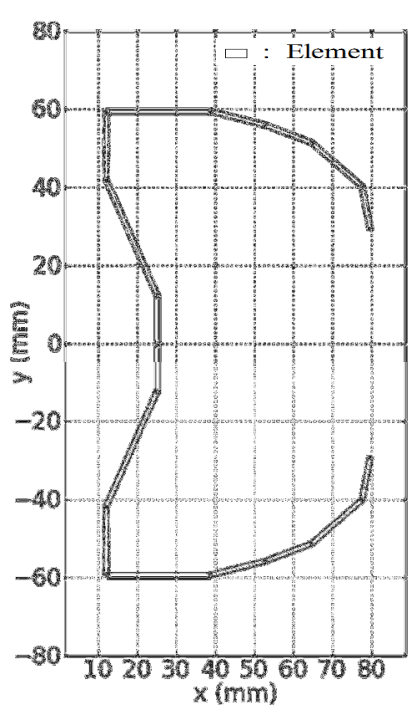

(a) $A_{s}=345.8 \mathrm{~mm}^{2}$ $N_{c}=75.5 \mathrm{kN}$ $N_{d} / A_{s}=218.3 \mathrm{MPa}$

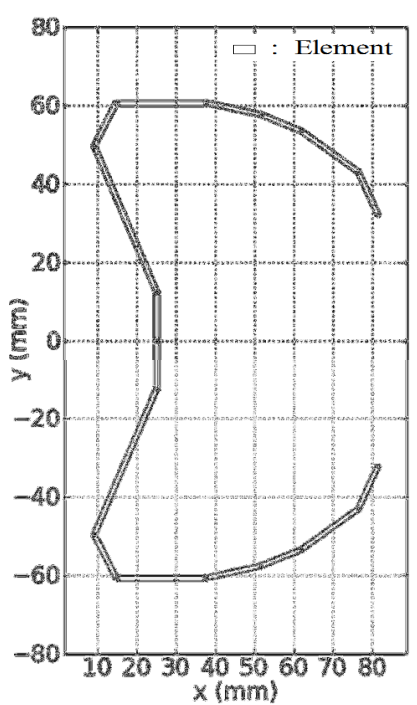

(b) $A_{s}=344.2 \mathrm{~mm}^{2}$ $N_{c}=75.0 \mathrm{kN}$ $N_{d} / A_{s}=217.9 \mathrm{MPa}$

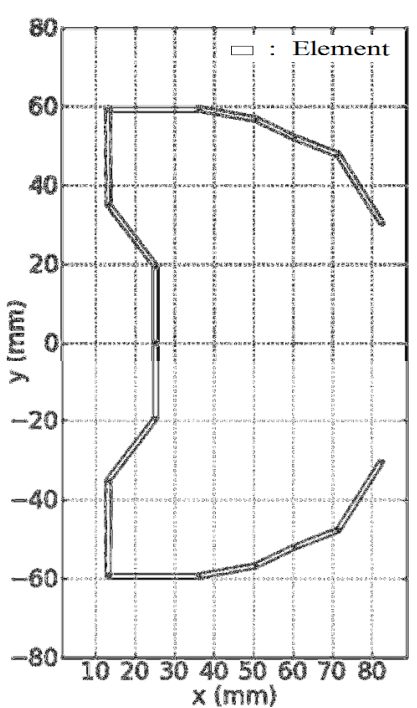

(c) $A_{s}=346.6 \mathrm{~mm}^{2}$ $N_{c}=74.6 \mathrm{kN}$ $N_{d} / A_{s}=215.2 \mathrm{MPa}$

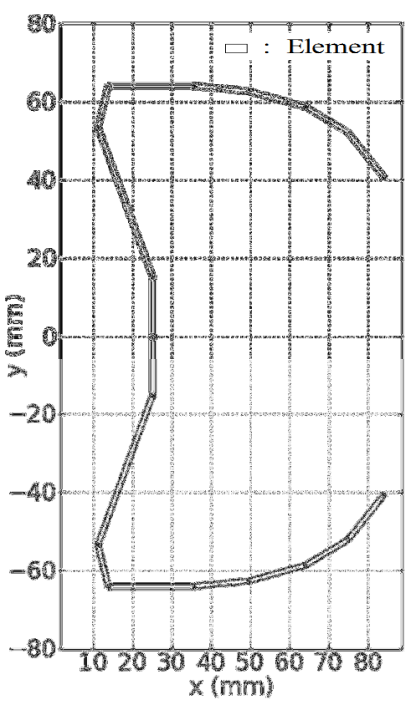

(d) $A_{s}=348.5 \mathrm{~mm}^{2}$ $N_{c}=74.9 \mathrm{kN}$ $N_{d} / A_{s}=214.9 \mathrm{MPa}$

Fig. 17: Optimised cross-sections for assembly Case III and $N_{e l e}=8$, (a, b) fittest cross-sections and (c, d) least fit cross-sections 
TABLES

Table 1: Maximum length of manufacturable elements per $N_{\text {ele }}$

\begin{tabular}{c|c|c|c}
\hline$N_{\text {ele }}$ & 4 & 6 & 8 \\
\hline$L_{\max }(\mathrm{mm})$ & 50 & 40 & 30 \\
\hline
\end{tabular}

Table 2. Analysed positon of fastening elements

\begin{tabular}{c|c|c|c|c|c|c}
\hline$N_{\text {ele }}$ & \multicolumn{2}{|c|}{4} & \multicolumn{2}{c|}{6} & \multicolumn{2}{c}{8} \\
\hline Fastening elements & $\begin{array}{c}\text { Vertical } \\
\text { web }\end{array}$ & $\begin{array}{c}\text { Horizontal } \\
\text { flange }\end{array}$ & $\begin{array}{c}\text { Vertical } \\
\text { web }\end{array}$ & $\begin{array}{c}\text { Horizontal } \\
\text { flange }\end{array}$ & $\begin{array}{c}\text { Vertical } \\
\text { web }\end{array}$ & $\begin{array}{c}\text { Horizontal } \\
\text { flange }\end{array}$ \\
\hline Sequential positions & '1'to '3' & '2' to '4' & '1' to '5' & '2' to '6' & '1'to '7' & '2' to '8' \\
\hline
\end{tabular}

Table 3: Parameters and results of fastening element/s position for all $N_{\text {ele }}$ and assembly cases

\begin{tabular}{|c|c|c|c|c|c|c|c|}
\hline $\begin{array}{l}\text { Assembly } \\
\text { case }\end{array}$ & $N_{\text {ele }}$ & $\begin{array}{c}\text { Initial } \\
\text { number of } \\
\text { individuals } \\
\text { per } \\
\text { position }\end{array}$ & $\begin{array}{l}\text { Number } \\
\text { of } \\
\text { positions } \\
\text { analysed }\end{array}$ & $\begin{array}{c}\text { Total } \\
\text { number of } \\
\text { individuals } \\
\text { per } \\
\text { generation }\end{array}$ & $\begin{array}{l}\text { Number of } \\
\text { analysed } \\
\text { generations } \\
\text { per run }\end{array}$ & $\begin{array}{c}\text { Number of } \\
\text { runs } \\
\text { converging } \\
\text { to the same } \\
\text { optimum } \\
\text { position }\end{array}$ & $\begin{array}{l}\text { Optimum } \\
\text { position }\end{array}$ \\
\hline \multirow{3}{*}{ Case I } & 4 & 400 & 3 & 1200 & 10 & 10 & Horizontal '2' \\
\hline & 6 & 250 & 5 & 1300 & 25 & 10 & Horizontal '2' \\
\hline & 8 & 200 & 7 & 1400 & 25 & 10 & Horizontal '3' \\
\hline \multirow{3}{*}{ Case II } & 4 & 300 & 6 & 1800 & 25 & 10 & $\begin{array}{l}\text { Horizontal '3' } \\
\text { - Vertical '2' }\end{array}$ \\
\hline & 6 & 240 & 15 & 3600 & 35 & 9 & $\begin{array}{l}\text { Horizontal '3' } \\
\text { - Vertical '2' }\end{array}$ \\
\hline & 8 & 200 & 28 & 5600 & 35 & 9 & $\begin{array}{l}\text { Horizontal '3' } \\
\text { - Vertical ' } 1 \text { ' }\end{array}$ \\
\hline \multirow{2}{*}{ Case III ${ }^{(1)}$} & 6 & 240 & 15 & 3600 & 35 & 9 & $\begin{array}{l}\text { Horizontal ' } 3 \text { ' } \\
\text { - Vertical ' } 1 \text { ' }\end{array}$ \\
\hline & 8 & 200 & 28 & 5600 & 35 & 8 & $\begin{array}{l}\text { Horizontal '4' } \\
\text { - Vertical ' } 1 \text { ' }\end{array}$ \\
\hline
\end{tabular}

Table 4: Average results over 10 runs for assembly Case I

\begin{tabular}{|c|c|c|c|c|c|c|c|}
\hline \multirow{2}{*}{$N_{\text {ele }}$} & \multicolumn{2}{|c|}{$\begin{array}{c}\text { Cross-sectional } \\
\text { area }\end{array}$} & \multicolumn{3}{|c|}{ Nominal member capacity } & \multirow{2}{*}{$\begin{array}{c}\text { Ultimate } \\
\text { compressive } \\
\text { stress } \\
N_{c} / A_{s} \\
(\mathrm{MPa})\end{array}$} & \multirow{2}{*}{$\begin{array}{c}\begin{array}{c}\text { Element } \\
\text { length } \\
\text { constraint }\end{array} \\
g\left(L_{\text {ele }}\right)^{(3)}\end{array}$} \\
\hline & $\begin{array}{c}A_{s} \\
\left(\mathrm{~mm}^{2}\right)\end{array}$ & $\begin{array}{l}\text { CoV } \\
(\%)\end{array}$ & $\begin{array}{c}N_{c} \\
(\mathrm{kN})\end{array}$ & $\begin{array}{c}\text { Error }^{(2)} \\
(\%)\end{array}$ & $\begin{array}{l}\text { CoV } \\
(\%)\end{array}$ & & \\
\hline 4 & 343.9 & 0.30 & 75.1 & 0.24 & 0.28 & 218.4 & $3.3 \times 10^{-4}$ \\
\hline 6 & 339.4 & 0.16 & 75.0 & 0.18 & 0.25 & 221.0 & $3.5 \times 10^{-4}$ \\
\hline 8 & 339.6 & 0.49 & 75.1 & 0.22 & 0.38 & 221.1 & $8.7 \times 10^{-4}$ \\
\hline$\infty^{(1)}$ & 337.4 & 0.25 & 75.1 & 0.21 & 0.24 & 222.6 & - \\
\hline
\end{tabular}

\footnotetext{
(1): Algorithm ran without manufacturing and assembly constraints (see [5] for reference)

(2): Absolute error when compared to $75 \mathrm{kN}$

(3): Element length constraint per half cross-section expressed as the $3^{\text {rd }}$ term in Eq. (5) without $\alpha_{L}$
} 
Table 5: Average results over 10 runs for assembly Case II

\begin{tabular}{|c|c|c|c|c|c|c|c|}
\hline \multirow{2}{*}{$N_{\text {ele }}$} & \multicolumn{2}{|c|}{$\begin{array}{c}\text { Cross-sectional } \\
\text { area }\end{array}$} & \multicolumn{3}{|c|}{ Nominal member capacity } & \multirow{2}{*}{$\begin{array}{c}\text { Ultimate } \\
\text { compressive } \\
\text { stress } \\
N_{c} / A_{s} \\
(\mathrm{MPa})\end{array}$} & \multirow{2}{*}{$\begin{array}{c}\begin{array}{c}\text { Element } \\
\text { length } \\
\text { constraint }\end{array} \\
g\left(L_{\text {ele }}\right)^{(3)}\end{array}$} \\
\hline & $\begin{array}{c}A_{s} \\
\left(\mathrm{~mm}^{2}\right)\end{array}$ & $\begin{array}{l}\text { CoV } \\
(\%)\end{array}$ & $\begin{array}{c}N_{c} \\
(\mathrm{kN})\end{array}$ & $\begin{array}{c}\text { Error }^{(2)} \\
(\%)\end{array}$ & $\begin{array}{l}\text { CoV } \\
(\%)\end{array}$ & & \\
\hline 4 & 361.6 & 0.41 & 75.2 & 0.34 & 0.54 & 208.0 & $2.0 \times 10^{-3}$ \\
\hline 6 & 340.3 & 0.20 & 75.0 & 0.17 & 0.30 & 220.4 & $9.1 \times 10^{-4}$ \\
\hline 8 & 338.9 & 0.20 & 75.0 & 0.08 & 0.12 & 221.3 & 0.0 \\
\hline$\infty^{(1)}$ & 337.4 & 0.25 & 75.1 & 0.21 & 0.24 & 222.6 & - \\
\hline
\end{tabular}

(1): Algorithm ran without manufacturing and assembly constraints (see [5] for reference)

(2): Absolute error when compared to $75 \mathrm{kN}$

${ }^{(3)}$ : Element length constraint per half cross-section expressed as the $3^{\text {rd }}$ term in Eq. (5) without $\alpha_{L}$

Table 6: Average results over 10 runs for assembly Case III

\begin{tabular}{|c|c|c|c|c|c|c|c|c|}
\hline \multirow{2}{*}{$N_{\text {ele }}$} & \multicolumn{2}{|c|}{$\begin{array}{c}\text { Cross-sectional } \\
\text { area }\end{array}$} & \multicolumn{3}{|c|}{ Nominal member capacity } & \multirow{2}{*}{$\begin{array}{c}\text { Ultimate } \\
\text { compressive } \\
\text { stress } \\
N_{c} / A_{s} \\
(\mathrm{MPa})\end{array}$} & \multirow{2}{*}{$\begin{array}{c}\begin{array}{c}\text { Element } \\
\text { length } \\
\text { constraint }\end{array} \\
g\left(L_{e l e}\right)^{(4)}\end{array}$} & \multirow{2}{*}{$\begin{array}{c}\begin{array}{c}\text { Utility } \\
\text { clearance } \\
\text { constraint }\end{array} \\
g(y)^{(5)}\end{array}$} \\
\hline & $\begin{array}{c}A_{s} \\
\left(\mathrm{~mm}^{2}\right)\end{array}$ & $\begin{array}{l}\text { CoV } \\
(\%)\end{array}$ & $\begin{array}{c}N_{c} \\
(\mathrm{kN})\end{array}$ & $\begin{array}{c}\text { Error }^{(3)} \\
(\%)\end{array}$ & $\begin{array}{l}\text { CoV } \\
(\%)\end{array}$ & & & \\
\hline $4^{(2)}$ & 361.6 & 0.41 & 75.2 & 0.34 & 0.54 & 208.0 & $2.0 \times 10^{-3}$ & 0.0 \\
\hline 6 & 348.8 & 0.41 & 75.0 & 0.07 & 0.08 & 215.0 & $0.8 \times 10^{-4}$ & 0.0 \\
\hline 8 & 346.0 & 0.37 & 75.1 & 0.22 & 0.32 & 217.1 & $2.4 \times 10^{-4}$ & $2.7 \times 10^{-3}$ \\
\hline$\infty^{(1)}$ & 337.4 & 0.25 & 75.1 & 0.21 & 0.24 & 222.6 & - & - \\
\hline
\end{tabular}

(1): Algorithm ran without manufacturing and assembly constraints (see [5] for reference)

(2): The results are replicated from $N_{\text {ele }}=4$ for Case II (Table 5)

${ }^{(3)}$ : Absolute error when compared to $75 \mathrm{kN}$

${ }^{(4)}$ : Element length constraint per half cross-section expressed as the $3^{\text {rd }}$ term in Eq. (6) without $\alpha_{L}$

${ }^{(5)}$ : Utility constraint per half cross-section expressed as the $4^{\text {th }}$ term in Eq. (6) without $\alpha_{D}$

Table 7: Comparison to conventional lipped Cee-sections

\begin{tabular}{|c|c|c|c|c|c|c|c|}
\hline \multirow[b]{2}{*}{$\begin{array}{c}\text { Assembly category } \\
\text { by cross-sectional } \\
\text { area }\end{array}$} & \multicolumn{6}{|c|}{ Conventional lipped channel section } & \multirow[b]{2}{*}{$\begin{array}{l}\text { Difference in } \\
\text { capacity } \\
(\%)\end{array}$} \\
\hline & $\begin{array}{l}\text { Depth } \\
(\mathrm{mm})\end{array}$ & $\begin{array}{l}\text { Width } \\
(\mathrm{mm})\end{array}$ & $\begin{array}{l}\text { Lip } \\
(\mathrm{mm})\end{array}$ & $\begin{array}{l}\text { Thick- } \\
\text { ness } \\
(\mathrm{mm})\end{array}$ & $\begin{array}{l}\text { Cross- } \\
\text { section } \\
\text { area } \\
\left(\mathrm{mm}^{2}\right)\end{array}$ & $\begin{array}{l}\text { Nominal } \\
\text { member } \\
\text { capacity } \\
(\mathrm{kN})\end{array}$ & \\
\hline Case I, $N_{\text {ele }}=4$ & 146.9 & 62.7 & 14.3 & 1.2 & $343.9^{(1)}$ & 34.7 & 116 \\
\hline Case II \& III, $N_{e l e}=4$ & 156.2 & 65.1 & 14.8 & 1.2 & $361.6^{(2)}$ & 37.4 & 101 \\
\hline
\end{tabular}

